\title{
Review Article \\ Photodynamic Antimicrobial Chemotherapy for Root Canal System Asepsis: A Narrative Literature Review
}

\author{
P. Diogo, ${ }^{1}$ T. Gonçalves, ${ }^{1,2}$ P. Palma, ${ }^{1}$ and J. M. Santos ${ }^{1}$ \\ ${ }^{1}$ Faculty of Medicine, University of Coimbra (FMUC), Avenida Bissaya Barreto, 3000-075 Coimbra, Portugal \\ ${ }^{2}$ Centre for Neuroscience and Cell Biology (CNC), University of Coimbra, Coimbra, Portugal \\ Correspondence should be addressed to P. Diogo; patriciadiogofmed@gmail.com
}

Received 1 July 2015; Revised 8 October 2015; Accepted 4 November 2015

Academic Editor: Steven Jefferies

Copyright @ 2015 P. Diogo et al. This is an open access article distributed under the Creative Commons Attribution License, which permits unrestricted use, distribution, and reproduction in any medium, provided the original work is properly cited.

\begin{abstract}
Aim. The aim of this comprehensive literature review was to address the question: Does photodynamic therapy (PDT) improve root canal disinfection through significant bacterial reduction in the root canal system? Methodology. A comprehensive narrative literature review was performed to compare PDT effect with sodium hypochlorite as the comparative classical irrigant. Two reviewers independently conducted literature searches using a combination of medical subject heading terms and key words to identify relevant studies comparing information found in 7 electronic databases from January 2000 to May 2015. A manual search was performed on bibliography of articles collected on electronic databases. Authors were contacted to ask for references of more research not detected on the prior electronic and manual searches. Results. The literature search provided 62 titles and abstracts, from which 29 studies were related directly to the search theme. Considering all publications, 14 (48\%) showed PDT to be more efficient in antimicrobial outcome than $\mathrm{NaOCl}(0.5-6 \%$ concentration) used alone and $2(7 \%)$ revealed similar effects between them. Toluidine blue and methylene blue are the most used photosensitizers and most commonly laser has $660 \mathrm{~nm}$ of wavelength with a $400 \mathrm{~nm}$ diameter of intracanal fiber. Conclusions. PDT has been used without a well-defined protocol and still remains at an experimental stage waiting for further optimization. The level of evidence available in clinical studies to answer this question is low and at high risk of bias.
\end{abstract}

\section{Introduction}

The main goal of endodontic treatment is to prevent and, when required, to cure apical periodontitis and maintain or reestablish periapical tissue health [1]. To accomplish this objective, it is mandatory to control the microbial load inside the root canal system. The chances of a favourable outcome with endodontic treatment are significantly higher if infection is eradicated effectively by chemomechanical preparation before the root canal is obturated. However, if positive cultures can be obtained from the root canal at the time of root filling, there is a higher risk of treatment failure [2]. In an attempt to improve disinfection, an interappointment dressing has been advocated to diminish the percentage of root canals with no cultivable microorganisms in comparison to those only treated with chemomechanical preparation. Nevertheless, the two-visit treatment protocol did not improve the overall antimicrobial efficacy of the treatment [3]. Indeed, in all cases where viable microorganisms remain in the root canal system, the prognosis for repair is adversely affected $[2,3]$.

Presence of a smear layer after instrumentation reduces effectiveness of irrigants and temporary dressings in disinfecting dentinal tubules. Moreover, complexity of anatomy translated into root canal system with its isthmuses, ramifications, and fins [4] turns complete elimination of bacteria using instrumentation and irrigation into an almost impossible task. Besides, bacteria persisting in biofilms show diverse phenotypes when compared with planktonic cells, including increased resistance to antimicrobial agents [5]. It has been assessed that bacteria in biofilms are approximately 1000 -fold less susceptible to effects of commonly used antimicrobial agents than their planktonic equivalents and are highly unaffected with phagocytosis by immune system [6]. There 
are several mechanisms used by bacteria which allow them to adapt to the environment [7]. Biofilm formation [8], stress response [9], physiological adaptation [7], and the beginning of subpopulations of cells are among some of the adaptive mechanisms used by bacteria along with various systems involving the exchange of genetic material [10] between bacteria. These mechanisms can support bacterial survival under the limiting environments, such as that found in the root canal. One of the most relevant features of adaptation for oral bacteria is the adhesion to surfaces leading to the formation of plaque biofilms, which not only serves to aid in their retention but also results in increased survival rate [11]. Biofilms form when planktonic bacteria in a natural liquid phase are deposited on a surface containing an organic conditioning polymeric matrix or conditioning film [7]. In this dynamic process, several organisms coadhere to the surface [12] and grow with certain cells detaching from the biofilm over time. Biofilm formation in root canals, as postulated by Svensater and Bergenholtz [13], is probably initiated at the moment of the first invasion of the pulp chamber by planktonic oral organisms after some tissue breakdown.

Biofilm disruption and disinfection of root canals are the most critical steps during treatment of an infected root canal system, which are essential to avoid persistence of microbial infection and achieve endodontic success [14]. The mode of action and efficacy of a wide variety of cleaning, antimicrobial, and disinfecting agents such as $\mathrm{NaOCl}$, chlorhexidine, ethylenediamine tetraacetic acid (EDTA), citric acid, hydrogen peroxide, halogens, and ozone have been investigated [15-18]. Disinfecting agents and antimicrobial medicinal products routinely used in endodontics can be inactivated by dentin, tissue fluids, and organic matter $[6,19]$. Moreover, some microbial species, such as Enterococcus faecalis [20, 21] and Candida albicans [22, 23], show resistance to those agents and their efficacy is dependent on the concentration achieved and time of contact [24]. Most of these disinfectants with effective bactericidal activity are used at subtoxic level, but also at concentrations where toxicity is becoming a significant factor. Searching for new methods to provide extra disinfection for root canal system without cytotoxic effects and to improve treatment outcome, innovative techniques including various laser wavelengths [25], hydraulic [26], sonic, and ultrasonic irrigation [27-29], nanoparticles [30], inactivation of efflux pumps [31], and photodynamic therapy (PDT) has been proposed in literature.

PDT was discovered by chance at the very beginning of the twentieth century, when a combination of nontoxic dyes exposed to visible light resulted in microorganism cell death. As reviewed by Henderson and Dougherty in 1992 [32], Oscar Raab, a medical student working with Professor Herman Von Tappeiner in Munich, introduced the concept of microbial cell death induced by interaction of light and chemicals [32]. During the course of Raab's study, he demonstrated that the combination of light and dyes was much more effective in killing the microorganism Paramecium.

Those observations were repeated with a diversity of uniand multicellular organisms. Succeeding work in this laboratory coined the term photodynamic action and demonstrated presence of oxygen as an essential requisite for photosensitization to occur. Years later, Dougherty and coworkers clinically tested PDT in cutaneous/subcutaneous malignant tumours. However, it was John Toth who renamed this therapy as PDT. Combined effect of three elements, light, $P S$, and oxygen, has been termed photodynamic antimicrobial chemotherapy by Wainwright [33] and also recognized as antimicrobial photodynamic therapy [34] and photoactivated disinfection [35].

PDT uses a nontoxic dye, known as photosensitizer (PS), on a target tissue, which is consequently irradiated with a suitable visible light of the appropriate wavelength to excite the PS molecule to the singlet state in presence of oxygen to produce reactive oxygen species (ROS) [36]. When PS absorbs light, this excited state may then undergo intersystem crossing to the slightly lower energy, but the longer lived, triple state can undergo two kinds of pathways known as Type I (reacting with the substrate) and Type II (reacting with molecular oxygen) photoprocesses. Both pathways require oxygen.

The type 1 radical and reactive oxygen species pathway comprises an electron transfer step between the triplet PS and a substrate with generation of radical species. The finalist is then intercepted by ground state molecular oxygen yielding a variety of oxidized products. The baseline PS has two electrons in opposite spins (singlet state) in the low energy molecular orbital. Subsequent to the absorption of light, one of these electrons is boosted into a high-energy orbital but keeps its spin (first excited singlet state). This is a shortlived time species, nanoseconds, and can lose its energy by emitting light (fluorescence) or by internal conversion into heat. Type 1 pathway frequently involves initial production of superoxide anion by electron transfer from the triplet PS to molecular oxygen (monovalent reduction) initiating radical-induced damage in biomolecules. Superoxide is not particularly reactive in biological systems and does not by itself cause much oxidative damage but can react with itself to produce hydrogen peroxide and oxygen, a reaction known as dismutation that can be catalyzed by the enzyme superoxide dismutase (SOD). The way of the electron relocation between the PS and the substrate is controlled by the relative redox potentials of the two species.

Type 2 pathway, singlet oxygen, involves an electronic energy transfer process from the triplet PS to a receptor, most frequently oxygen, which is a triplet in its ground state. The final compound is converted to a highly reactive species, the singlet oxygen $\left({ }^{1} \mathrm{O}_{2}\right)$. The excited singlet state PS may also undergo the process known as intersystem crossing whereby the spin of the excited electron inverts to form the relatively long-lived, in terms of microseconds, excited triplet state that has parallel electron spins. The long lifetime of the PS triplet state is explained by the fact that the loss of energy by emission of light (phosphorescence) is a spin forbidden process, as the PS would move directly from a triplet to a singlet state. Photosensitized processes of types 1 and 2 depend on the initial involvement of radical intermediates that are subsequently scavenged by oxygen or the generation of the highly cytotoxic singlet oxygen $\left({ }^{1} \mathrm{O}_{2}\right)$ by energy transfer from the photoexcited sensitizer. It is difficult to determine 
without doubt which of these two mechanisms is more prevalent; both types of reactions can happen simultaneously and the ratio between them depends on three singular features: oxygen, substrate concentration, and PS type [37].

Hamblin and Hasan in 2004 [36] stated that antimicrobial PS can be divided into three categories: (I) those that strongly bind and penetrate the microorganisms (chlorin e6), (II) those that bind weakly as toluidine blue (TB) and methylene blue (MB), and (III) those that do not demonstrate binding at all such as rose bengal (RB). Understanding these mechanisms of action is essential because, in bacterial cells, outer membrane damage plays an imperative role, differently from mammalian cells, where the main targets for PDT are lysosomes, mitochondria, and plasma membranes [38]. Typically, neutral anionic or cationic PS molecules could powerfully destroy Gram-positive bacteria, whereas only cationic PS or strategies which attack the Gram-negative permeability barrier in combination with noncationic PS are able to kill multiple logs of Gram-negative species [39]. This difference in susceptibility between species in the two bacterial types is explained by their cell wall physiology. To understand better the PDT effect in those microorganisms, it is very important to analyse in detail the microbial cell walls. In Gram-positive bacteria, the cytoplasmic membrane is surround by a relatively porous peptidoglycan layer and lipoteichoic acid that allows the PS to cross. Different from this, the Gram-negative bacteria cell envelope consists of an inner and an outer membrane which are separated by a peptidoglycan layer. The outer membrane forms an effective permeability barrier between the cell and the environment and tends to restrict the binding and penetration of several PS. Fungi are provided with a thick cell wall that includes beta glucan and chitin offering a permeability barrier. In terms of PDT efficacy, in fungal wall, it was described as having an intermediate behavior between Gram-positive and Gram-negative bacteria [40]. On the basis of these considerations, it appears that Gram-negative bacteria represent the most challenging targets for any form of antimicrobial treatment. The mechanism of action of basic polymer PS conjugates is thought to be that of self-promoted uptake pathway [41]. In this method, cationic molecules first dislocate the divalent cations, such as calcium $\left(\mathrm{Ca}^{2+}\right)$ and magnesium $\left(\mathrm{Mg}^{2+}\right)$, from their position on the outer membrane where they act as an anchor for the negatively charged lipopolysaccharides molecules [40, 41]. The debilitated outer membrane becomes slightly more permeable and allows even more of the cationic PS to gain access thus steadily increasing the disorganizations of the permeability barrier increasing PS uptake with each additional binding. It is thought that host cells only gradually take up cationic molecules by the process of endocytosis, while their uptake into bacteria is relatively fast [39]. Further important observation that has been made about these cationic antimicrobial PS concerns their selectivity for microbial cells compared to host mammalian cells [37]. These findings are relevant, because photoaction occurs in direct contact with membranes [42]. The PS efficiency in generating ROS within membranes is dependent on the intrinsic characteristics of the PS in aqueous solution as well as their partition in the membrane [42]. The early attack of singlet oxygen in membranes lipids is by the specific reaction with double bonds to form allylic hydroperoxides; the efficiency of this reaction is dependent on the lowest ionization potential of the olefins and also on the availability of allylic hydrogens [42]. Photodynamic lipid peroxidation is an oxidative degradation of cell membrane lipids, also known as photoperoxidation, and it has been related to several microbial cytotoxic effects, such as increased ion permeability, fluidity loss, inactivation of membrane proteins, and cross-linking, which disrupts the intracellular homeostasis. Consequently, necrosis is induced as a cell death process. A probable explanation is that PS bound to the membrane and generates most of the singlet oxygen, ${ }^{1} \mathrm{O}_{2}$, involved in photoperoxidation [43] highlighting the double selectivity (light and PS cellular localization) and the fact that it works in multiresistant strains and does not encourage resistance [42]. PDT's lethal action is based on photochemical production of ROS and not thermal and cavitation effects, as is the case with high power laser therapy [44]. One of several PDT's advantages clinically is the absence of thermal side effects in periradicular tissues [45] and this property of PDT aspect makes it highly effective in eradicating microorganisms such as bacteria [45], viruses [46], and fungi [47] without causing damage of adjacent tissues due to overheating [45].

In recent years, PDT has been applied in several areas, particularly in periodontology [48-50], in general dentistry [51] and also in endodontic field as an adjunct of classical irrigation solutions in root canal disinfection $[52,53]$. These studies suggest PDT's potential as a therapeutic weapon, which aims to support endodontic antimicrobial treatment, especially enhancing irrigation solutions effect. The purpose of this narrative comprehensive literature review is to answer the focused question, "Is antimicrobial PDT efficacy better than that of sodium hypochlorite's in root canal treatment?" For this analysis of the literature, we selected and analysed 29 studies using antimicrobial PDT in endodontic field, highlighting methodologies used and their reported effectiveness and efficacy.

\section{Materials and Methods}

2.1. Criteria in Selection of Studies. For this comprehensive narrative literature review [54], eligibility criteria were (I) articles published in English language; (II) original papers; (III) experimental studies (in vitro and ex vivo); (IV) clinical studies (in vivo); and finally (V) scientific reports of PDT efficacy in root canal disinfection/asepsis. The exclusion criteria were (I) unpublished data, (II) conference papers, (III) historic reviews, (IV) letters to editor, and (V) papers due to PDT outcomes in other fields (outside of endodontics).

As a first step, the aim was to investigate the terms "Endodontic", "Photodynamic Therapy", and "Antimicrobial Disinfection". Briefly, we used PubMed to identify Medical Subject Headings (MeSH) terms corresponding to each term. Nevertheless, MeSH terms use is not common to all articles, making this search method infeasible. Then, exhaustive automated searches of Cochrane Collaboration, Evidence Based Dentistry (EBD), Journal of Evidence-Based Dental Practice (JEBDP), NHS Evidence, and PubMed (Figure 1) were performed from January 2000 up to and including May 2015 


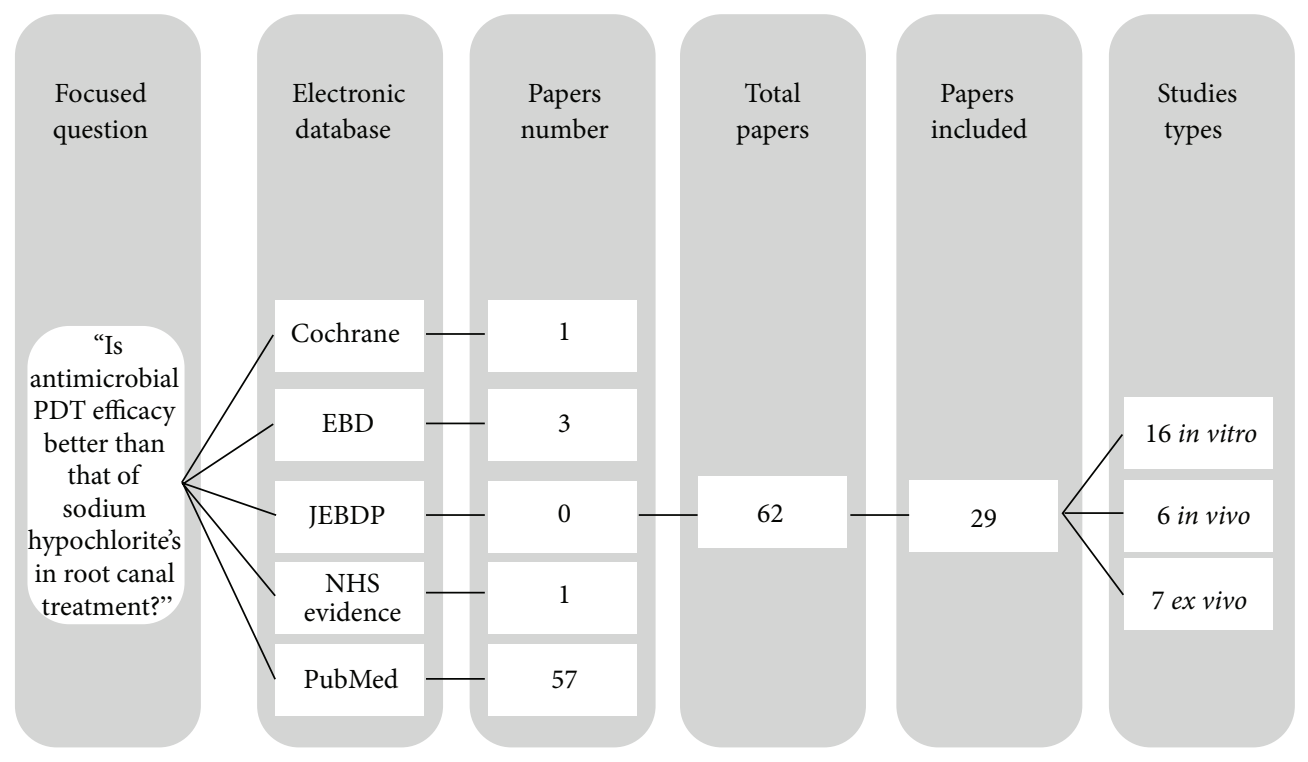

FIGURE 1: Identification of studies used in this narrative review.

using various combinations of the following key indexing terms: (a) endodontic photodynamic therapy; (b) antimicrobial photodynamic therapy; (c) photo-activated disinfection; (d) light-activated disinfection; (e) laser-assisted photosensitization; (f) root canal disinfection; and (g) endodontic lasers.

Titles and abstracts of all articles resulting from electronic search were screened independently and in duplicate by 2 reviewers. The review itself was performed to reject articles that did not meet inclusion criteria. Any disagreement between reviewers was solved via debate, although in specific cases of disagreement that were not resolved with discussion, opinion of a senior commentator was required. Hand searching of reference lists of original and reviewed articles that were found to be relevant was also performed.

In a second step, full-text copies of all remaining articles were obtained and further meticulous assessment was performed independently by each reviewer to determine whether or not they were eligible for this study based on the specific inclusion and exclusion criteria cited above and proven for agreement.

Quality evaluation of randomized clinical trials and observational studies was performed using STROBE [55] (strengthening the reporting of observational studies in epidemiology) and CONSORT [56] (consolidated standards of reporting trials) statement criteria, respectively.

\section{Results}

3.1. PDT Antimicrobial Efficacy in Included Studies. Literature search provided 62 titles and abstracts; from those, 29 studies concerned this theme: 16 were performed in in vitro conditions, 6 were in vivo studies, and the last 7 readings were ex vivo. From all 29 papers included in this review, 16 (55.2\%) were in vitro studies (Table 1 ).
In data processing, authors classified all studies in three categories: category I, in vitro; category II, in vivo; and finally, category III, ex vivo, to describe and clarify studies' details. In category I, 16 in vitro studies, only 5 (31\%) [57-61] reveal best antimicrobial PDT outcomes when compared with sodium hypochlorite $(\mathrm{NaOCl})$ in range of 0.5 to $6 \%$. Only one study performed by Nagayoshi et al. [62] reveals equal results between PDT and $\mathrm{NaOCl}$; the remaining 10 (62.5\%) studies [63-72] showed PDT outcomes unhelpful when compared with $\mathrm{NaOCl}$ as a classical irrigant solution, in concentration range of 0.5 to $6 \%$. In category II, $6(21 \%)$ papers $[35,58,73-$ 76] were analysed (Table 2).

All were performed in the human dentition, five [35, $58,73,74,76]$ were performed in permanent dentition, and only one was achieved in deciduous teeth by Prabhakar et al. [75]. All studies in category II (100\%) presented that PDT efficacy overthrew (0.5-2.5\%) NaOCl. Considering tooth type and its influence in PDT efficacy outcomes, Garcez et al. group [58, 74] and Jurič et al. [76] tested only permanent uniradicular human teeth (incisors and canines) as samples. However, Prabhakar et al. [75] considered deciduous molars as a prerequisite for his study. Finally, Bonsor et al. [35, 73] used not only uniradicular but also permanent multiradicular teeth. In terms of endodontic diagnosis, Garcez et al. [58] in his first study used patients with necrotic pulps and periapical lesion; then, in 2010, his group [74] performed a second study to assess PDT efficacy in teeth with previous endodontic treatment, endodontic retreatment. Jurič et al. [76] in 2014 evaluated PDT antimicrobial outcomes efficacy applied also in endodontic retreatment. Both studies $[74,76]$ revealed PDT outcomes near $100 \%$ effective.

In category III (ex vivo), 7 (24\%) papers [5, 77-82] were analysed (Table 3 ).

Based on this, $3(43 \%)$ studies $[5,78,79]$ revealed superior PDT outcomes compared to $0.5-6 \%$ of $\mathrm{NaOCl}$ and in one study by Xhevdet et al. group [81] showed $2.5 \% \mathrm{NaOCl}$ 


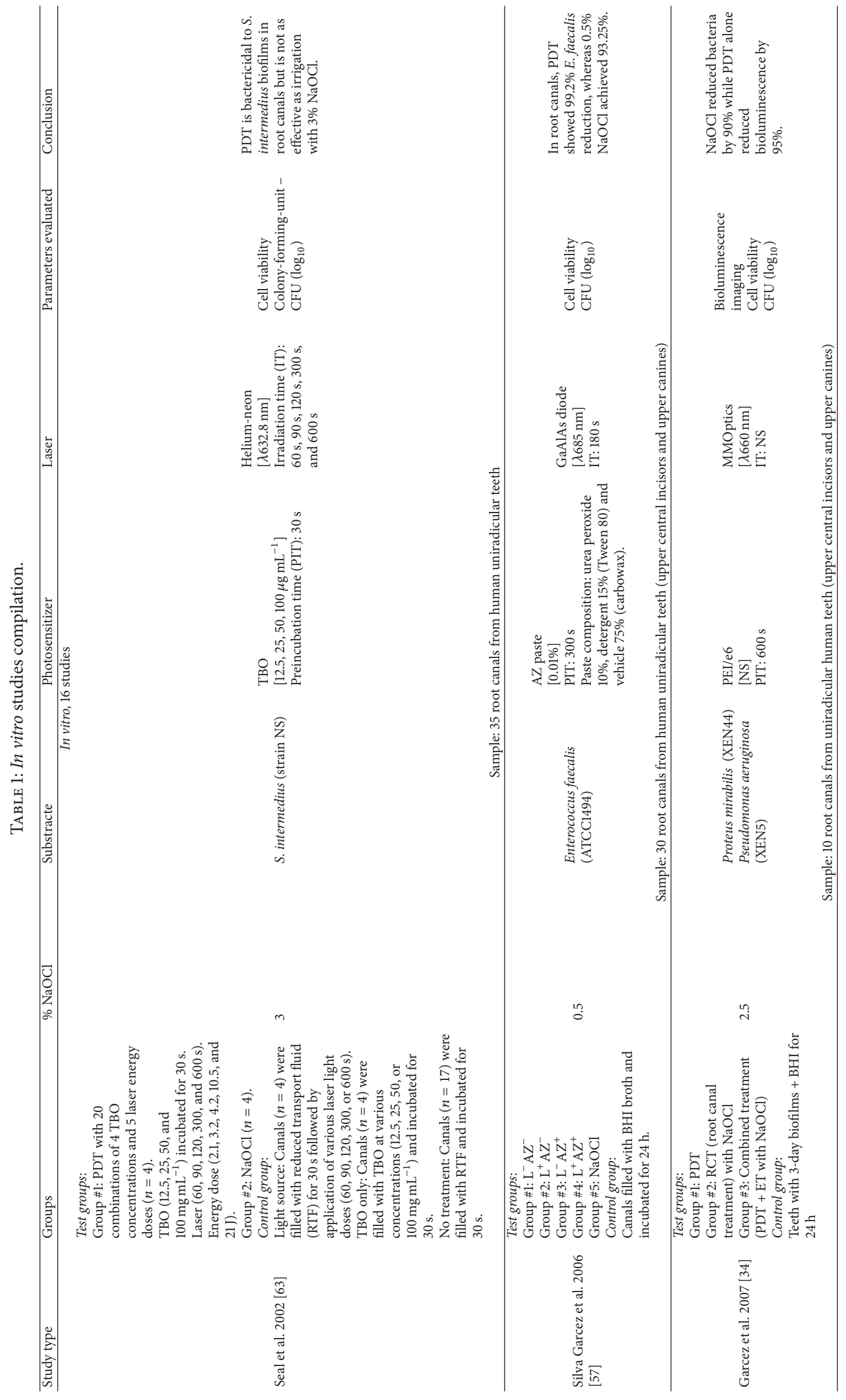




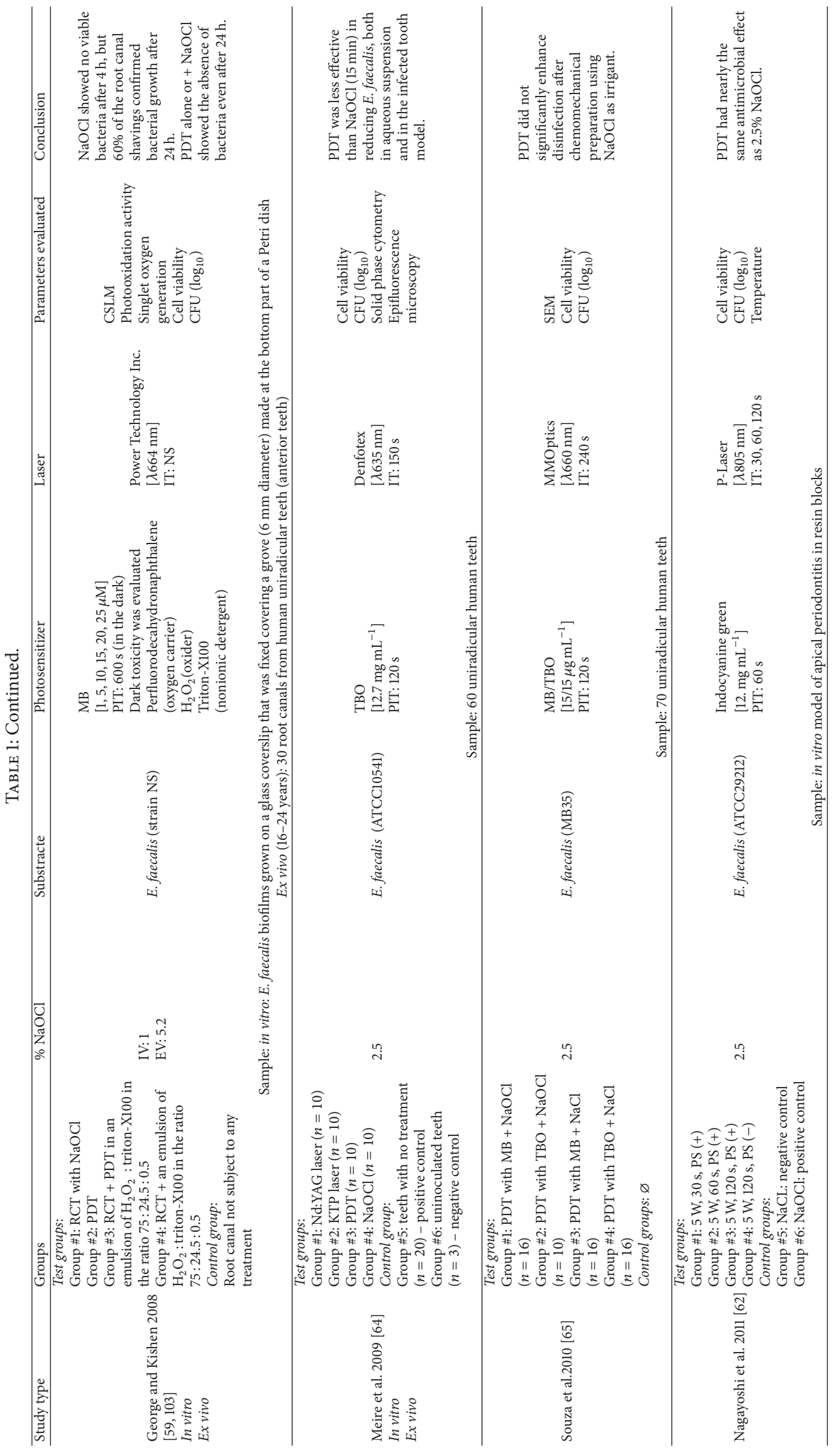




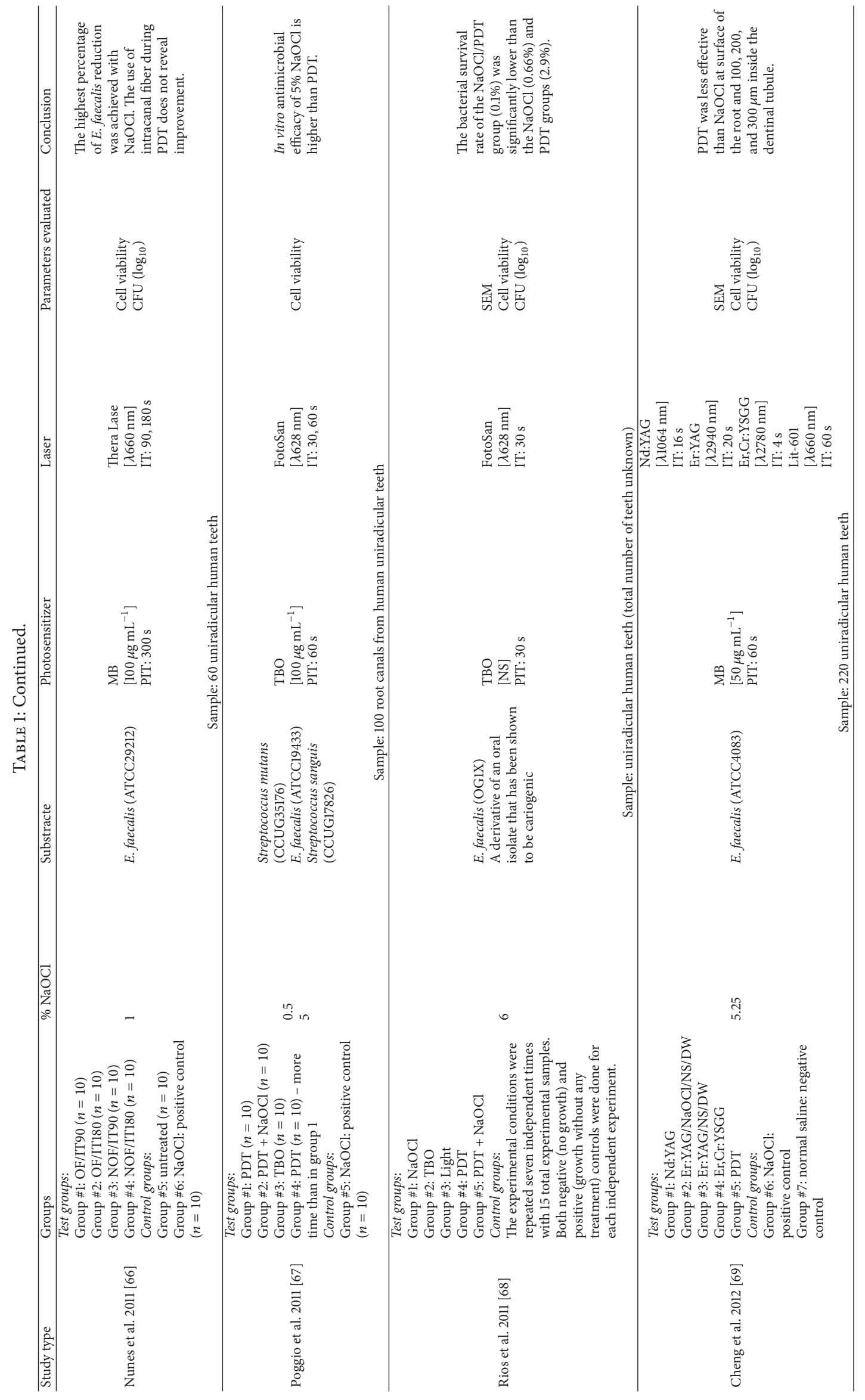




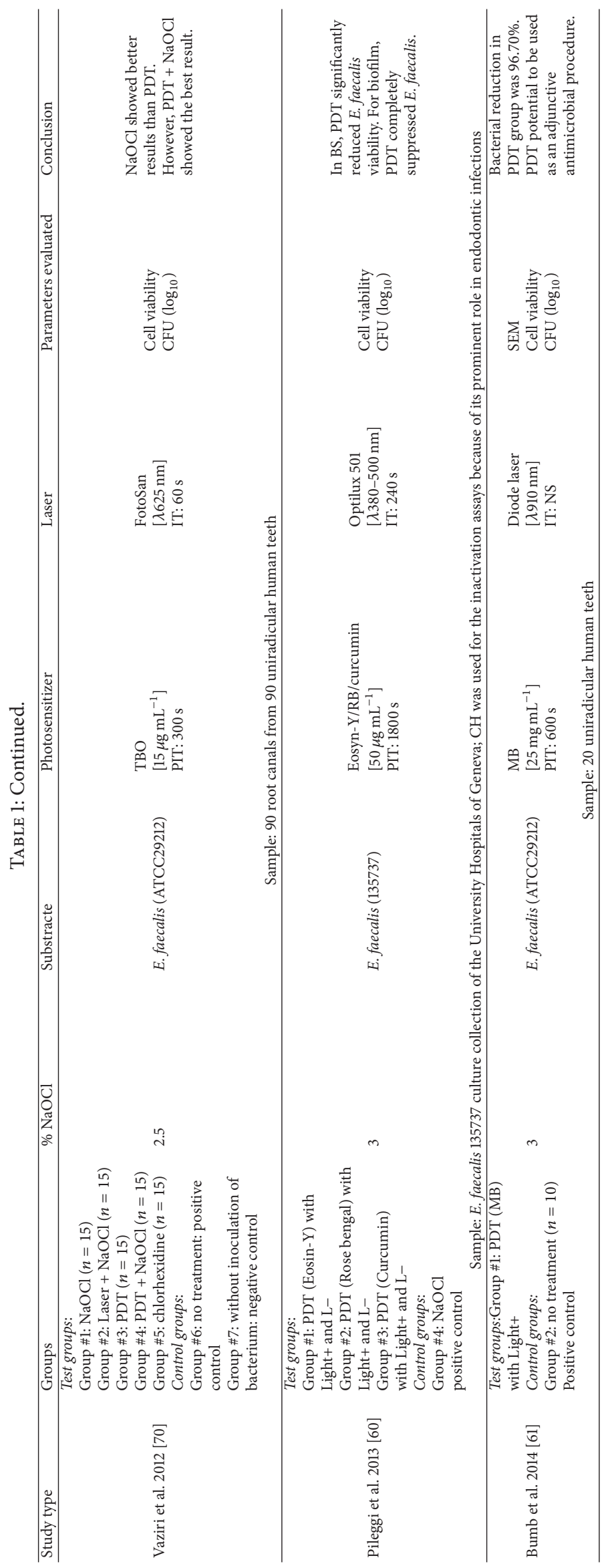




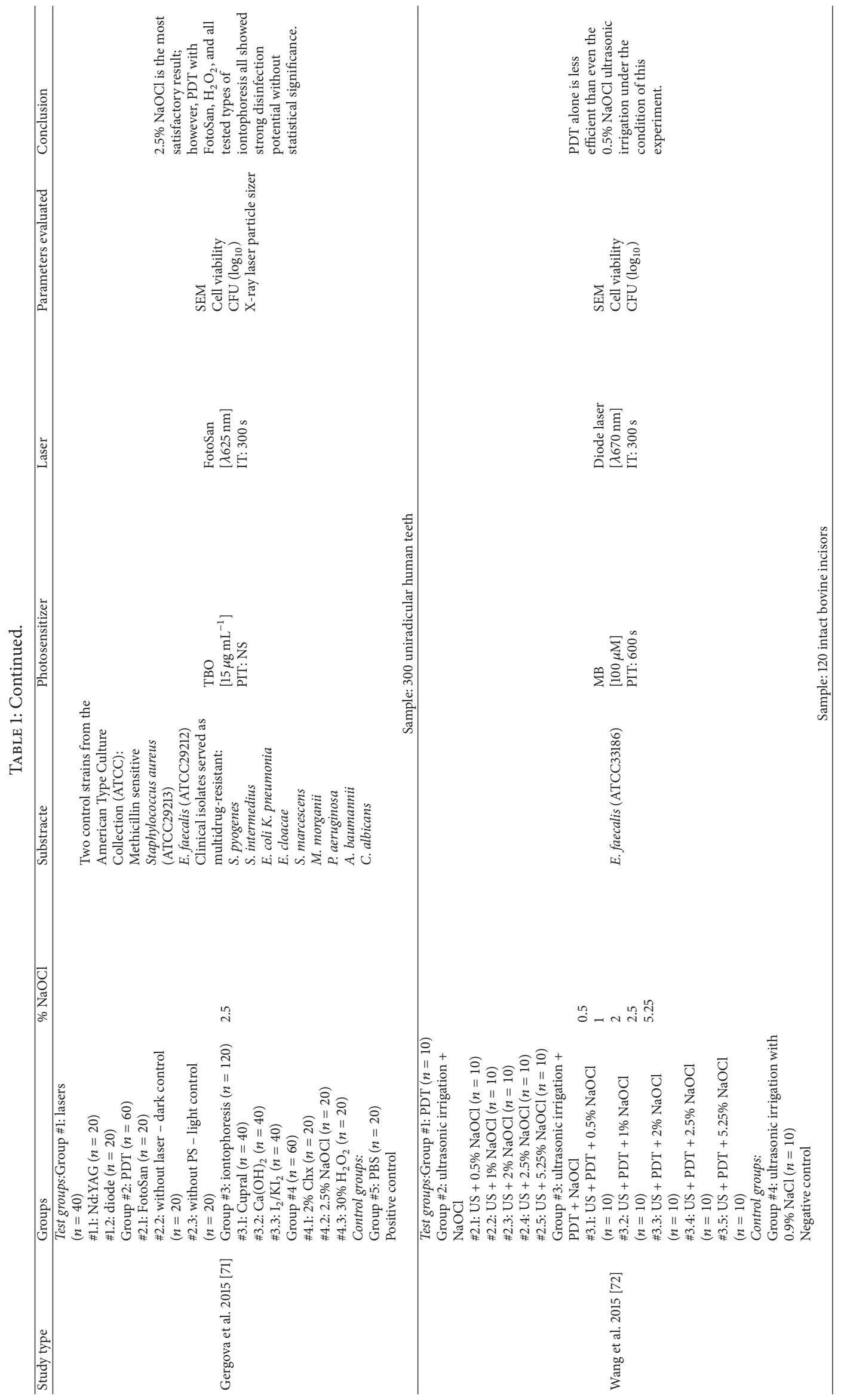




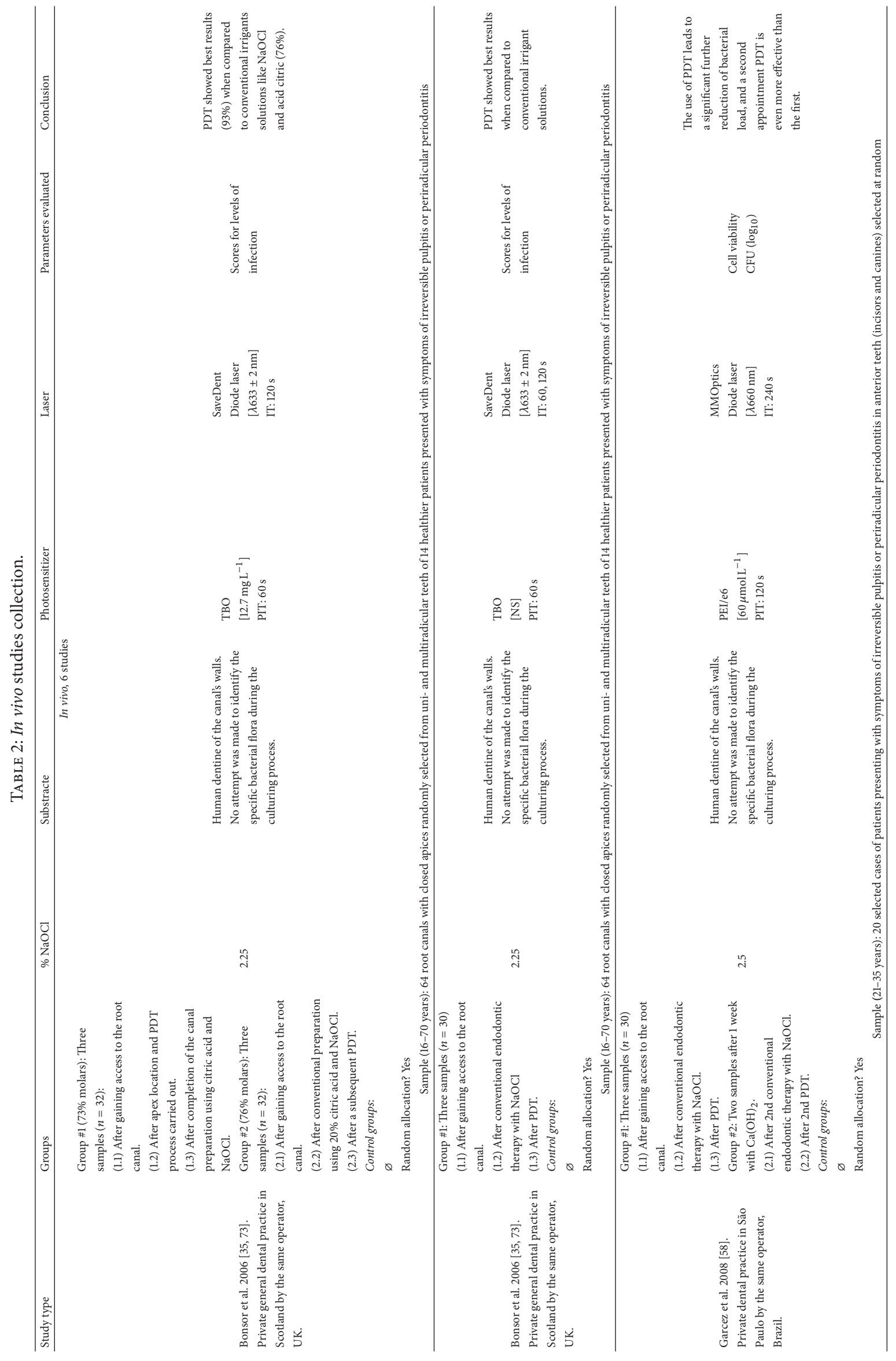




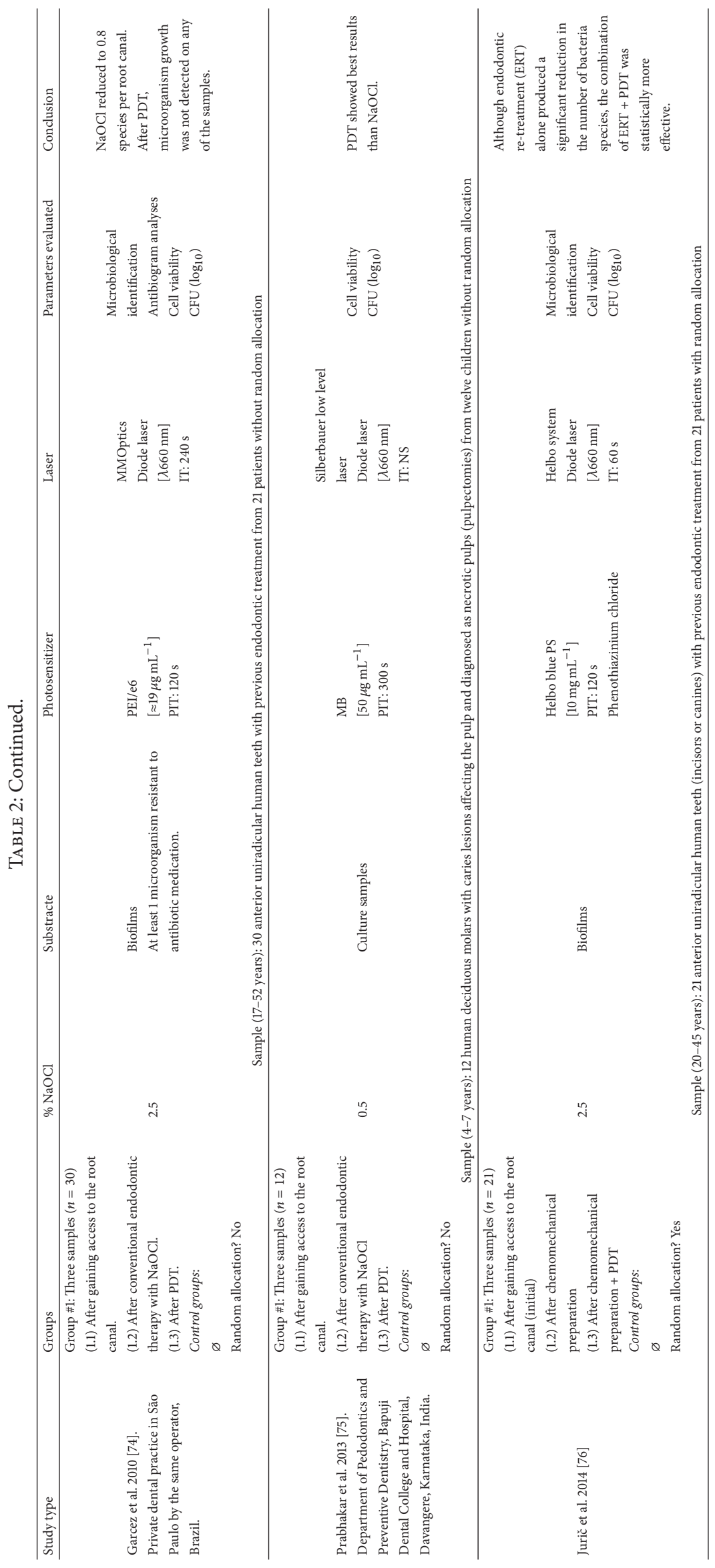




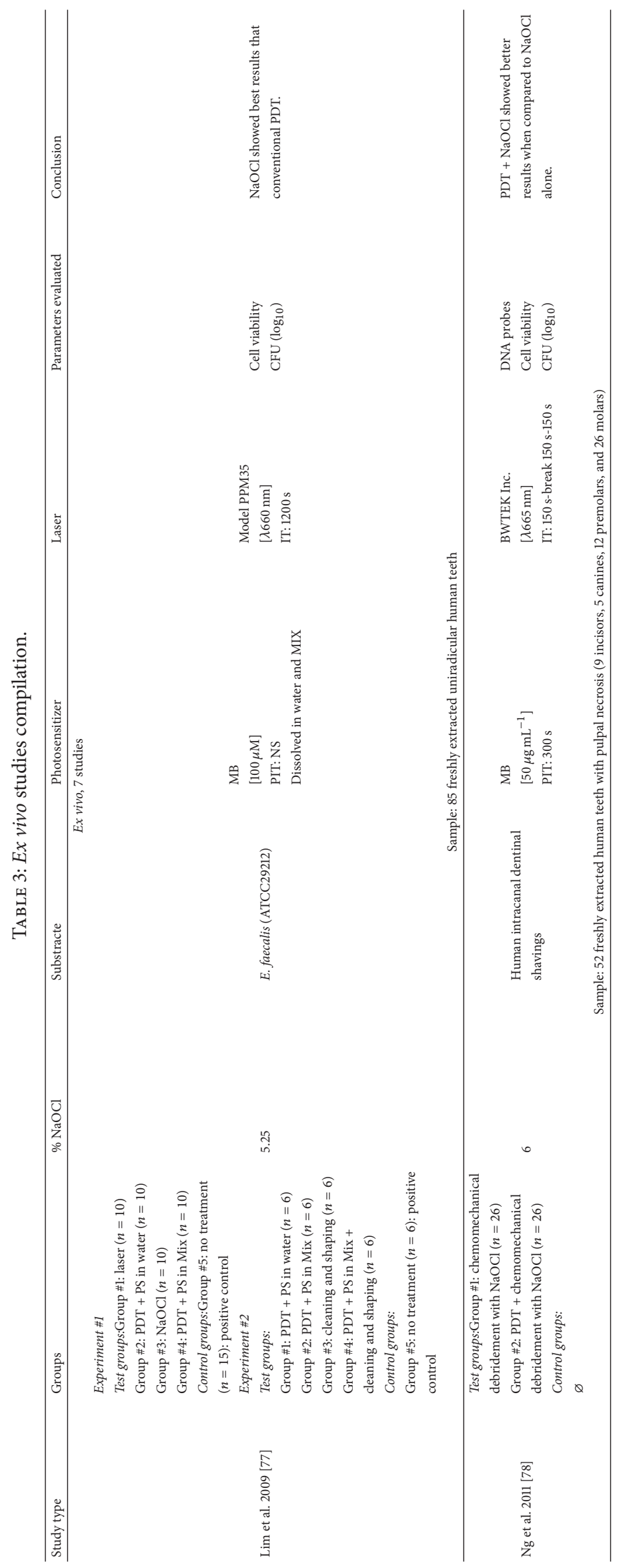




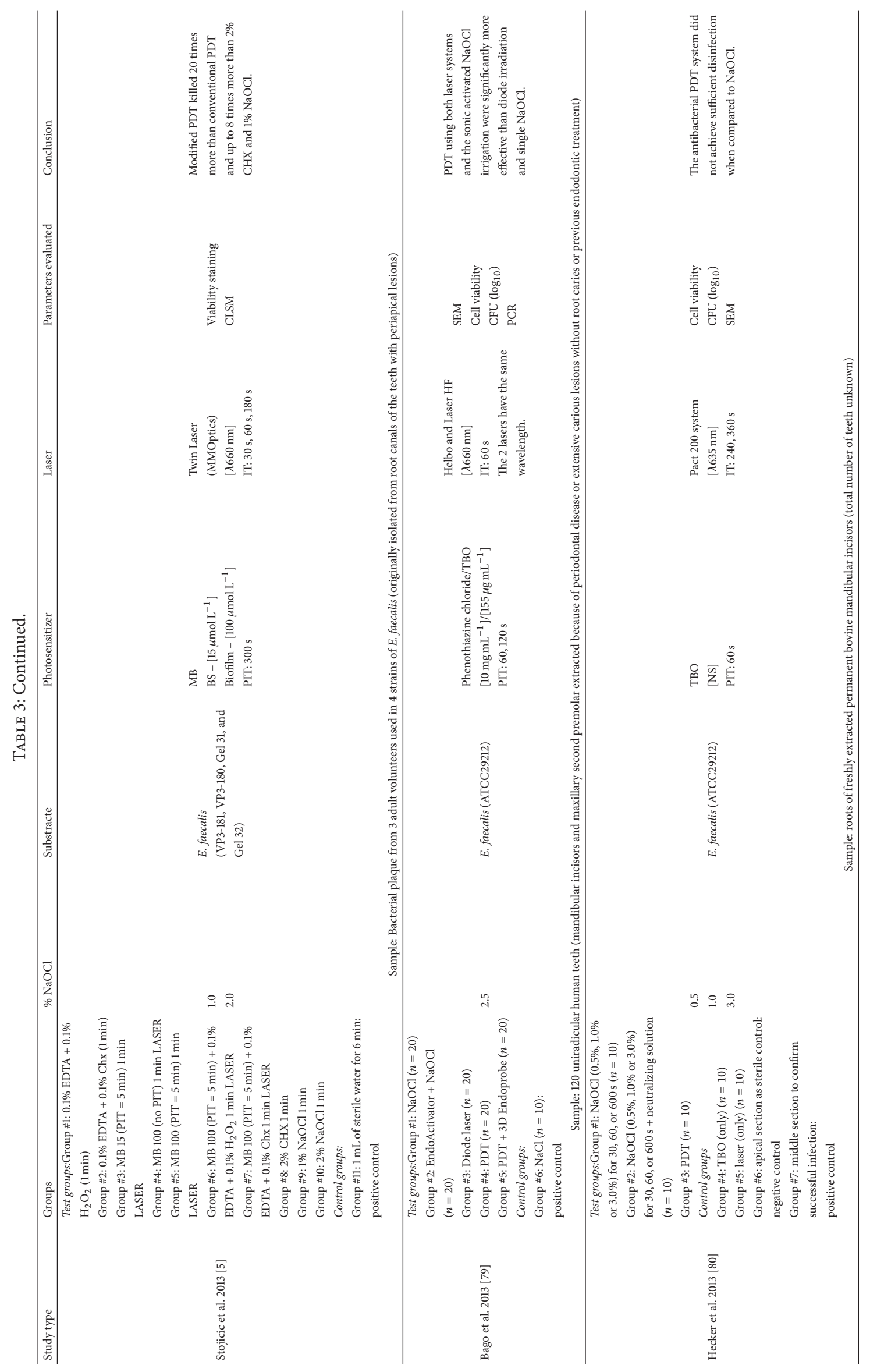




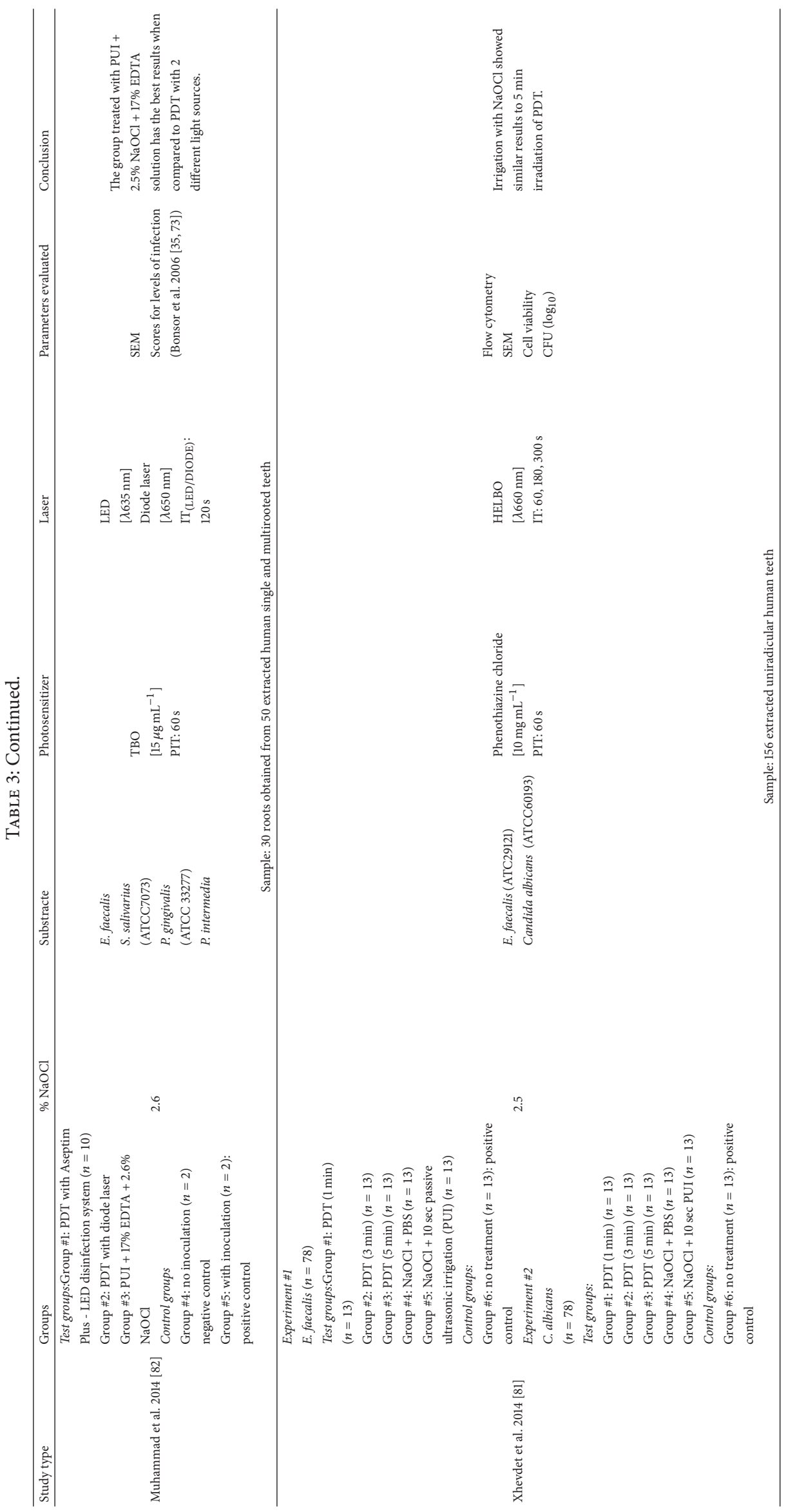


TABLE 4: PDT microbial reduction outcomes.

\begin{tabular}{|c|c|c|c|}
\hline Author & Study type & Microorganisms & $\begin{array}{c}\text { Efficacy } \\
\left(\% \text { or } \log _{10}\right)\end{array}$ \\
\hline Seal et al. $2002[63]$ & In vitro & S. intermedius & $5 \log _{10}$ \\
\hline Bonsor et al. $2006[35,73]$ & In vivo & Polymicrobial infected teeth & 96.7 \\
\hline Bonsor et al. $2006[35,73]$ & In vivo & Polymicrobial infected teeth & 91 \\
\hline Silva Garcez et al. 2006 [57] & In vitro & E. faecalis & 99.2 \\
\hline Garcez et al. 2007 [34] & In vitro & P. mirabilis and $P$. aeruginosa & 98 \\
\hline Garcez et al. 2008 [58] & In vivo & Polymicrobial human dentine of the canal's walls & 99.9 \\
\hline George and Kishen $2008[59,103]$ & In vitro/ex vivo & E. faecalis & 100 \\
\hline Lim et al. 2009 [77] & Ex vivo & E. faecalis & 99.99 \\
\hline Meire et al. 2009 [64] & In vitro/ex vivo & E. faecalis & $1-1.5 \log _{10}$ \\
\hline Souza et al. 2010 [65] & In vitro & E. faecalis & 99.48 \\
\hline Garcez et al. 2010 [74] & In vivo & Polymicrobial infected teeth & 100 \\
\hline Nagayoshi et al. 2011 [62] & In vitro & E. faecalis & 99.99 \\
\hline Ng et al. $2011[78]$ & Ex vivo & Human intracanal dentinal shavings & 70 \\
\hline Nunes et al. 2011 [66] & In vitro & E. faecalis & 99.41 \\
\hline Poggio et al. 2011 [67] & In vitro & S. mutans; E. faecalis, and S. sanguis & 91.49 \\
\hline Rios et al. 2011 [68] & In vitro & E. faecalis & 99.9 \\
\hline Bago et al. 2013 [79] & Ex vivo & E. faecalis & 99.99 \\
\hline Cheng et al. 2012 [69] & In vitro & E. faecalis & 96.96 \\
\hline Pileggi et al. 2013 [60] & In vitro & E. faecalis & 96.7 \\
\hline Stojicic et al. 2013 [5] & Ex vivo & E. faecalis & 100 \\
\hline Vaziri et al. 2012 [70] & In vitro & E. faecalis & $82.3 \%$ \\
\hline Hecker et al. 2013 [80] & Ex vivo & E. faecalis & Not specified \\
\hline Prabhakar et al. 2013 [75] & In vivo & Polymicrobial infected teeth & 99.99 \\
\hline Bumb et al. 2014 [61] & In vitro & E. faecalis & 96.7 \\
\hline Gergova et al. 2015 [71] & In vitro & $\begin{array}{l}\text { S. aureus; E. faecalis; S. pyogenes; S. intermedius; E. coli; } \\
\text { K. pneumonia; E. cloacae; S. marcescens; M. morganii; } P \text {. } \\
\text { aeruginosa; A. baumannii; C. albicans }\end{array}$ & $42-54$ \\
\hline Jurič et al. 2014 [76] & In vivo & Polymicrobial infected teeth & 100 \\
\hline Muhammad et al. 2014 [82] & Ex vivo & E. faecalis; S. salivarius; P. gingivalis; P. intermedia & Not specified \\
\hline Xhevdet et al. 2014 [81] & Ex vivo & E. faecalis and C. albicans & 71.59 \\
\hline Wang et al. 2015 [72] & In vitro & E. faecalis & $5.20 \log _{10}$ \\
\hline
\end{tabular}

irrigation showed similar results to $5 \mathrm{~min}$ irradiation of PDT, $10 \mathrm{mg} \mathrm{mL}^{-1}$ phenothiazine chloride as PS irradiated with $660 \mathrm{~nm}$ light source.

Considering all 29 publications, 14 of them (48\%) [5, $34,35,57-61,73-76,78,79]$ showed best PDT antimicrobial outcome compared to (0.5-6\%) $\mathrm{NaOCl}$ used alone; 2 (7\%) $[62,81]$ papers reveal similar effects between them and the last $13(45 \%)[63-72,77,80,82]$ studies revealed supremacy of sodium hypochlorite $(0.5-6 \%)$.

3.2. Antimicrobial PDT Outcomes. The present narrative literature review was based on hypothesis that antimicrobial PDT efficacy was better than sodium hypochlorite in root canal asepsis. Considering all studies chronologically organized in Table 4, 48\% (14 papers) showed PDT is more efficient than $\mathrm{NaOCl}(0.5-6 \%$ concentration) used alone and 7\% (2 papers) reveal similarity in antimicrobial outcome effects between them.
On the other hand, 45\% (13 studies) of studies reveal supremacy of sodium hypochlorite. From all studies, it must be observed that $55.2 \%$ (16 studies) were conducted at in vitro conditions, revealing preferential experimental phase where PDT remains in the last two decades. This must be taken into consideration, when comparing with clinical PDT studies, in which evidence reveals unanimous evidence supremacy of PDT over $\mathrm{NaOCl}$.

3.3. Evaluation Parameters. The 29 studies analysed for this review revealed assessment of antimicrobial PDT efficacy was done through several parameters, from microbiological evaluation (classical analysis) to recent advanced imaging approaches. At the beginning, bacteriological experimental in vitro studies presented results through colony-forming units (CFU). This approach overcomes limitation of direct microscopic counting of bacterial cells, where all cells, dead and live, are counted; CFU estimates only viable cells of each 
group, before and after treatment, in planktonic suspensions and biofilms. Results are given as CFU/mL (colony-forming units per millilitre) for liquids. This approach was used in 24 studies (83\%) [34, 57-66, 68-72, 74-81]; Bonsor et al. [35, 73] used bacterial load scores, instead of the usual CFU, to evaluate PDT antimicrobial efficacy in clinical studies. Muhammad et al. [82] in 2014 over an ex vivo study elected the same evaluation unit as in Bonsor et al. studies, repeating bacterial score, complemented with microbiological identification.

Scanning electron microscopic (SEM) in vitro investigations have demonstrated the penetration of bacteria up to $1000 \mu \mathrm{m}$ into dentinal tubules and hence it is very difficult for normal irrigants to penetrate till this depth. $\mathrm{NaOCl}$ can penetrate in a range of $60-150 \mu \mathrm{m}$ into dentinal tubules and of Nd:YAG laser at a range of $400-850 \mu \mathrm{m}$. Enterococcus faecalis is known to colonize dentinal tubules up to depth of $600-1000 \mu \mathrm{m}$ and conventional irrigants cannot penetrate more than $100 \mu \mathrm{m}$ [83]. With SEM, Bumb et al.'s [61] in vitro study revealed bacteria found till the depth of $980 \mu \mathrm{m}$ (control group) and in PDT group achieved a depth of 890-900 $\mu \mathrm{m}$ free from microorganisms, which revealed PDT as a promising root canal disinfection approach. SEM is a remarkably versatile technique, which reproduces the exact morphology of structures, but as the main disadvantage of dehydration of the sample. It was used in 10 (34\%) studies [61, $65,68,69,71,72,79-82$ ] and ESEM (environmental scanning electron microscope) [84] which allows preservation of the sample before and after light irradiation was not used in any study. CSLM was used only in one study of George and Kishen [59] showing capability of obtaining in-focus images from selected depths allowing three-dimensional reconstruction of topologically complex objects with a specific hardware analysis. The same study [59] also evaluated dark toxicity (detail described in photosensitizers subchapter) and ROS production. PDT antimicrobial killing can be mediated by type I and type II reactions, although singlet oxygen is the predominant chemical entity causing cell death. Analysis and quantification of singlet/reactive oxygen species detection seem to be an excellent methodology to quantify antimicrobial PDT outcomes. However, of all studies analysed, only George and Kishen [59] performed ROS quantification and state that the increased photooxidation potential and singlet oxygen generation were thought to have collectively contributed towards the biofilm matrix disruption [59] and bacterial inactivation.

3.4. Photosensitizers. Photosensitizers (PS), which were preferentially located at the bacterial cytoplasmic membrane, have been found to be very potent photoantimicrobial agents. One important exception is represented by acridines [36], such as proflavine or acridine orange, which mostly interpolate with DNA bases. Highest modifications of cell functions and morphology, triggered by photodynamic inactivation, are typically due to damaged membranous domains [36]. This pattern of photoinduced subcellular damage is in agreement with lack of mutagenic effects [85], as well as with absence of selection of photoresistant microbial strains even after several photosensitization treatments.

Methylene blue (MB), a well-established PS, has been used in PDT for targeting endodontic bacteria since 2007 [34] and remains as one of the most used; but the first PS used in endodontic field was toluidine blue (TBO) [63]. Hydrophilicity of $\mathrm{MB}$, along with its low molecular weight and positive charge, allows it to cross outer membrane of Gram-negative bacteria through porin channels $[33,86]$. MB predominantly interacts with anionic macromolecule lipopolysaccharide, resulting in generation of $\mathrm{MB}$ dimers, which participate in the photosensitization process. From all studies evaluated, 12 (41\%) $[35,63-65,67,68,70,71,73,79,80,82]$ used TBO as PS, while 10 (34\%) $[5,59,61,65,66,69,75,77,78,87]$ studies used MB. One study, elaborated by Souza et al. [65], used both $\mathrm{TBO}$ and $\mathrm{MB}$ as PS. The best antimicrobial PDT results were achieved with TBO and MB as PS in the same concentration, $15 \mu \mathrm{g} \mathrm{mL}^{-1}[5,65,70,71,82]$. All concentration variations are studied first in preliminary findings to obtain fluorescence characteristics [45] in ultraviolet-visible absorption spectra on a diode-array spectrophotometer to understand absorption pattern and to establish final concentration. In designing criteria for definition of second generation PS, an essential feature has been evaluated, dark toxicity [88]. It is clearly desirable that PS has zero or very low cytotoxicity in total absence of light and this indicates antimicrobial PDT efficacy results strictly from combination between PS and light source. Reviewing literature in this aspect, only one study from George and Kishen [59] had this aspect in mind.

The period of intimate contact between PS and substrate without irradiation, known as preincubation time (PIT), diverges in terms of PS used. It is also important that PIT is fixed in total absence of light, even natural light [88]. The most used TBO PIT was 60 seconds (s) $[35,67,73,80,82]$ from a range of 30-300 s (mean $=95.5 \mathrm{~s})$ and MB PIT most used was $300 \mathrm{~s}[5,66,75,78]$ from a range of $60-600 \mathrm{~s}($ mean $=353.3 \mathrm{~s})$.

3.5. Light. Phototherapy describes use of light in treatment of disease; photochemotherapy, on the other hand, involves a combination of administration of a photosensitizing agent followed by action of light on tissues in which the agent is located [89]. PDT kills microorganisms by combined action of visible light and a photosensitizing dye. From all 29 studies evaluated, laser wavelength gap referred to in literature was between 380 [60] and $910 \mathrm{~nm}$ [61] (mean $=650.8 \mathrm{~nm}$ ), while most used light source was a diode laser of $660 \mathrm{~nm}[5,34,58$, $65,66,69,74-77,79,81]$ wavelength. Some orthodox photosensitizers have lost their proficiency because they needed specific light source for each one and combination between them triggers the costs. Several examples can illustrate this aspect: Azpaste $(685 \mathrm{~nm})$ [57]; indocyanine green $(805 \mathrm{~nm})$ [62]; eosin-Y, and curcumin (380-500 nm) [60] which make them, nowadays, outdated.

In terms of commercial light sources, there are three diode lasers that authors would like to remark: Denfotex of $635 \mathrm{~nm}$ (SaveDent; Denfotex, Inverkeithing, UK) [64, 90, 91], Helbo of $660 \mathrm{~nm}$ (Helbo Photodynamic Systems, Grieskirchen, Austria) [91], and FotoSan emitting in the red spectrum with a power peak at $628 \mathrm{~nm}$ (FotoSan; CMS Dental, Copenhagen, Denmark) $[67,68,71]$. Delivery of PDT treatment with Denfotex, according to the manufacturer's recommendations, includes TBO as PS at a concentration of $12.7 \mathrm{mg} \mathrm{L}^{-1}$, applied 
in $120 \mathrm{~s}$ as preincubation time (PIT); followed by an irradiation time (IT) of $150 \mathrm{~s}$ with a laser output power of $100 \mathrm{~mW}$ using the spherical tip. Helbo system advocates Helbo Endo Blue PS, a MB dye, at a concentration of $10 \mathrm{mg} \mathrm{L}^{-1}$ fully covering the root canal with a PIT of $180 \mathrm{~s}$; after this time, according to the manufacturer's recommendations, excess PS dye should be removed and light source applied for an IT of $120 \mathrm{~s}$ and an output power of $75 \mathrm{~mW}$ with an attached 2D spot probe Helbo Photodynamic Systems. Meire et al. in 2012 [91] performed an in vitro study comparing Denfotex with Helbo. The same team [91] reported that log reduction with Helbo system was higher than with Denfotex; however, the best results were achieved with $2.5 \% \mathrm{NaOCl}$ for $300 \mathrm{~s}$. Several differences between the two systems were described and might account for the distinctive reduction outcomes in viable cells [91]. First, the PS dyes are chemically different; secondly, Helbo Blue PS is much more concentrated than Denfotex PS. Thirdly, following the PS application and the recommended PIT, the PS excess has to be removed with the Helbo system, dried canal [91], but not with the two other systems: Denfotex and FotoSan, where fiber is inserted in the liquid $[67,68,71,91]$. In the three PDT systems, all probes are different. While the Helbo systems 2D spot probe is designed for two-dimensional exposure, Denfotex and FotoSan tips emit in three dimensions and this has strong implications for energy densities at the target. Also the lasers wavelengths are slightly different. It seems that there is also a clear reduction in light exposure as irradiation time (IT): Denfotex (150 s) [91], Helbo (120 s) [91], and FotoSan (30 s) [67, 68, 71].

FotoSan uses only TBO as a FotoSan PS, available in three types of viscosities (low, medium, and high), all at the same concentration $\left(100 \mu \mathrm{g} \mathrm{mL}^{-1}\right)$ and the light source with an output power of $100 \mathrm{~mW}$. FotoSan was evaluated in $3(10.3 \%)$ studies $[67,68,71]$, curiously all conducted in in vitro conditions with FotoSan protocol IT of $30 \mathrm{~s}$.

Poggio et al. [67] tested $30 \mathrm{~s}$ and also $90 \mathrm{~s}$ of IT and declared that with the longer light exposure, it results in an increased percentage of bacterial reduction for different groups of Enterococcus faecalis, Streptococcus mutans, and Streptococcus sanguis strains. For this reason, this group admits that FotoSan needs to be applied into canal for at least $90 \mathrm{~s}$, because $30 \mathrm{~s}$ of irradiation showed lower performance when compared to PDT with IT of $90 \mathrm{~s}$, although the same group reveals that the best outcomes were achieved with PDT 30 s of IT combined with $5 \% \mathrm{NaOCl}$.

Irradiation time (IT) is an important issue to considerer and, in this parameter, PDT studies outcomes are very dissimilar with a range between $30 \mathrm{~s}[63,68]$ and $1800 \mathrm{~s}[60]$. Considering the most used wavelength of $660 \mathrm{~nm}$, preference irradiation time is in the range between $30 \mathrm{~s}$ [5] and $1200 \mathrm{~s}$ [77] ( mean = 223 s).

The last aspect considered in laser literature is the need for an intracanal fiber tip to spread light into root dentinal walls as well as within biofilms. From all studies analysed, only Nunes et al. [66] explored in vitro effectiveness of PDT with and without use of an intracanal optical fiber. Nunes et al. [66] concluded that, under experimental conditions, PDT was effective against $E$. faecalis, regardless of whether or not it is applied through an intracanal fiber. Considering the use of intracanal fiber, only $4(13.8 \%)$ studies $[63,70,75,80]$ were not performed with intracanal fiber (Table 5).

Prabhakar et al. [75], in these particular conditions, revealed in a clinical study that antimicrobial PDT performance is better than $0.5 \% \mathrm{NaOCl}$. When PDT is implemented in planktonic suspensions established in multiwells, light source was applied $20 \mathrm{~mm}$ [60] away from well. Considering intracanal fiber, fiber tip diameter most used was $400 \mathrm{~nm}$ [59, $62,64,72,77]$. In terms of intracanal fiber location inside root, it varies from full working length (WL) $[34,58,62,64,66,71$, $76,79,81,82]$, the most prevalent, to WL-1 millimeters ( $\mathrm{mm}$ ) $[57,74]$, WL-2 mm [61, 68], WL-3 mm [67-69], and WL$4 \mathrm{~mm}[35,73]$. Contemplating the same device, intracanal fiber, in terms of applying movements to itself or inserting endodontic tip static inside root canal to improve the best light diffusion through root canal [66]. The former was applied in 5 studies $[34,58,65,66,79]$ with spiral movements from apical to cervical and latter maintained static $[64,76,77]$ inside root canal orifice [77] or at WL $[64,76]$.

3.6. Disinfection Protocol. In literature, when PDT studies are accomplished in teeth, the majority of them are performed in human single rooted tooth specimens with no evidence of caries or defects and radicular pathology. Considering tooth type, there is only one study performed in deciduous teeth [75]; the majority was achieved in permanent uniradicular human teeth. However, four studies used not only uniradicular but also multiradicular teeth [35, 73, 78, 82]. Besides, decayed teeth are also studied in deciduous [75] and permanent teeth [79].

Slaughterhouse bovine teeth [80] are convenient to use in antimicrobial PDT studies because of their match with human dentine; more precisely, their dentinal tubules are very similar to human teeth in quantity, size, diameter, morphology, and density. Moreover, bovine teeth [12] are simple to acquire and reduced size makes handling easier; in this term, they were used in $2(7 \%)$ studies $[72,80]$. Only one study, performed by Nagayoshi et al. [62], was executed in a resin block which attempts to mimic an in vitro model of apical periodontitis.

In the most common experimental model, dental specimens are decoronated to a standard length of $12 \mathrm{~mm}$ [67, $68,78,79]$ although gap value is very wide, from $8[59,77]$ to $15 \mathrm{~mm}[66,81]$ or complete root canal length. Patency of apical foramina is established and then mechanical $[35,58$, $61,63-68,70,71,73,74,76,78,79,81,82]$ instrumentation is performed using nickel-titanium rotary files, predominantly in a coronoapical (crown-down) technique [35, 58, 61, 63$68,70,71,73,74,76,78,79,81,82]$ from canal orifice to apical third, until it reaches the value of master apical file (MAF) of $\mathrm{K}$ (Kerr) file $40[58,59,68,70]$. However, other MAF have been described, such as $35[57,79,81]$ and 30 [34].

In terms of irrigation with disinfecting agents, those are used for smear layer (SL) removal, lubrication, debris removal, and antimicrobial effects. SL is composed of organic and inorganic components like vital or necrotic pulp tissue, microorganisms, saliva, blood cells, and tooth structure. Among irrigation solutions, sodium hypochlorite $(\mathrm{NaOCl})$ 


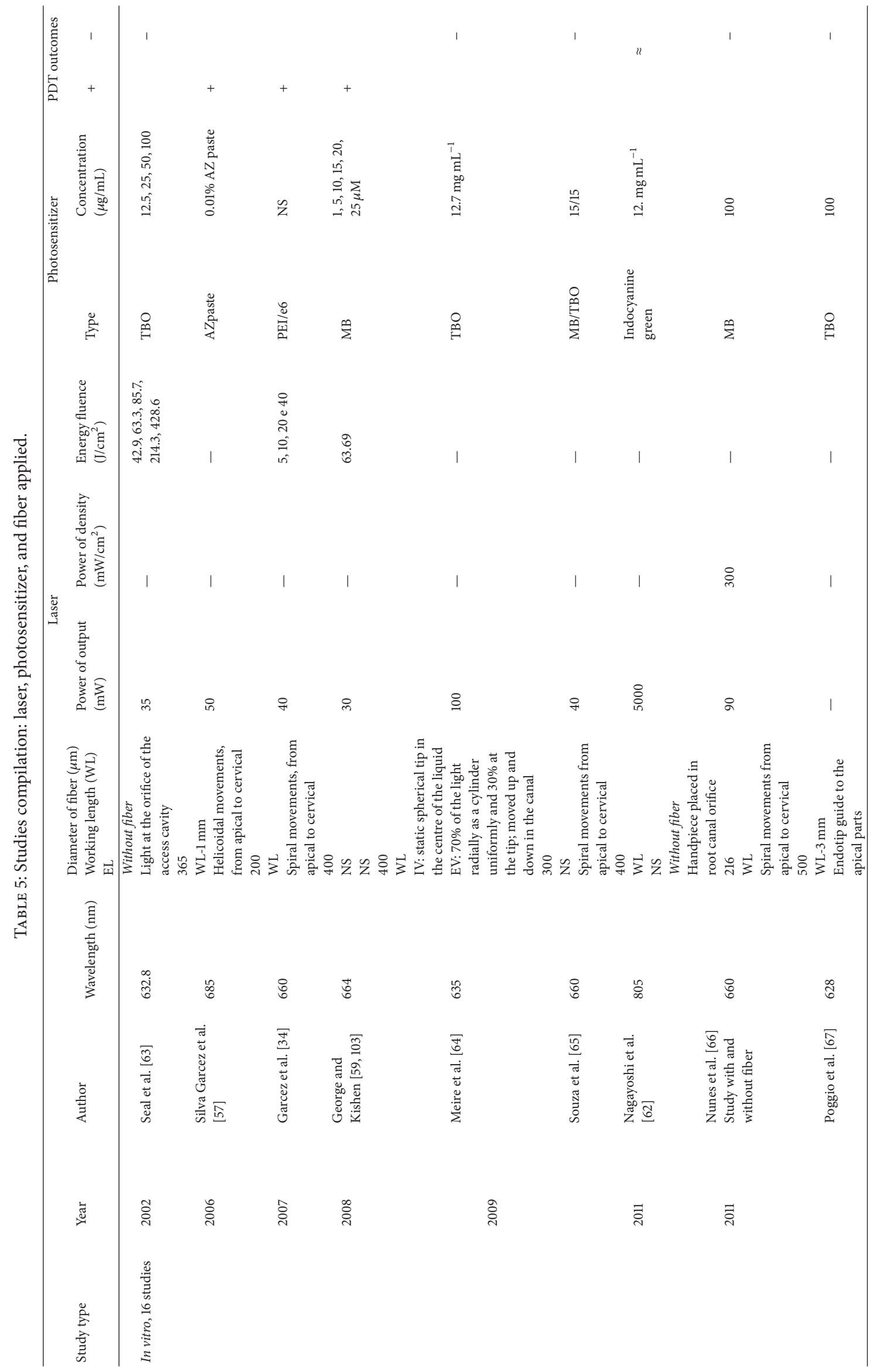




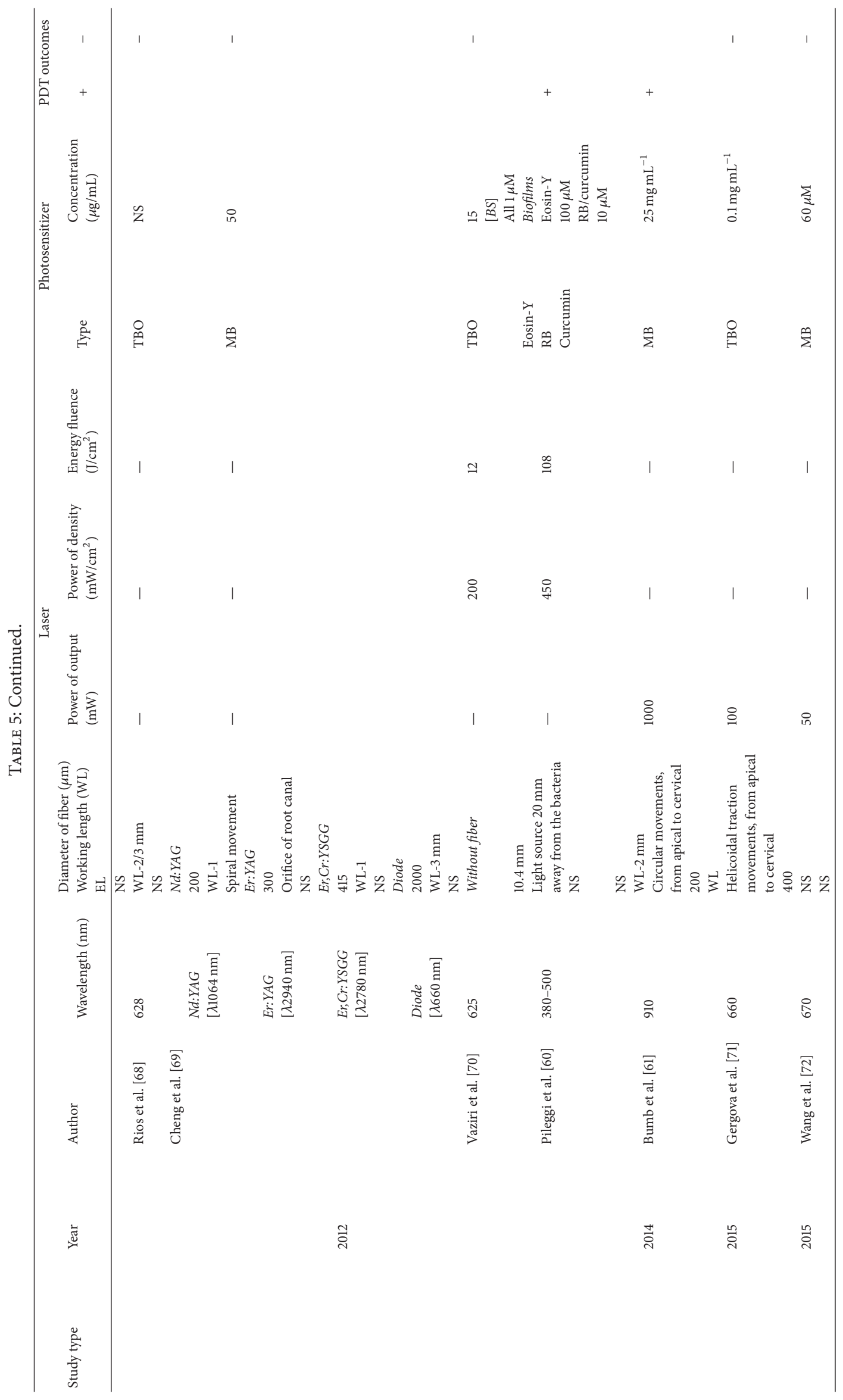




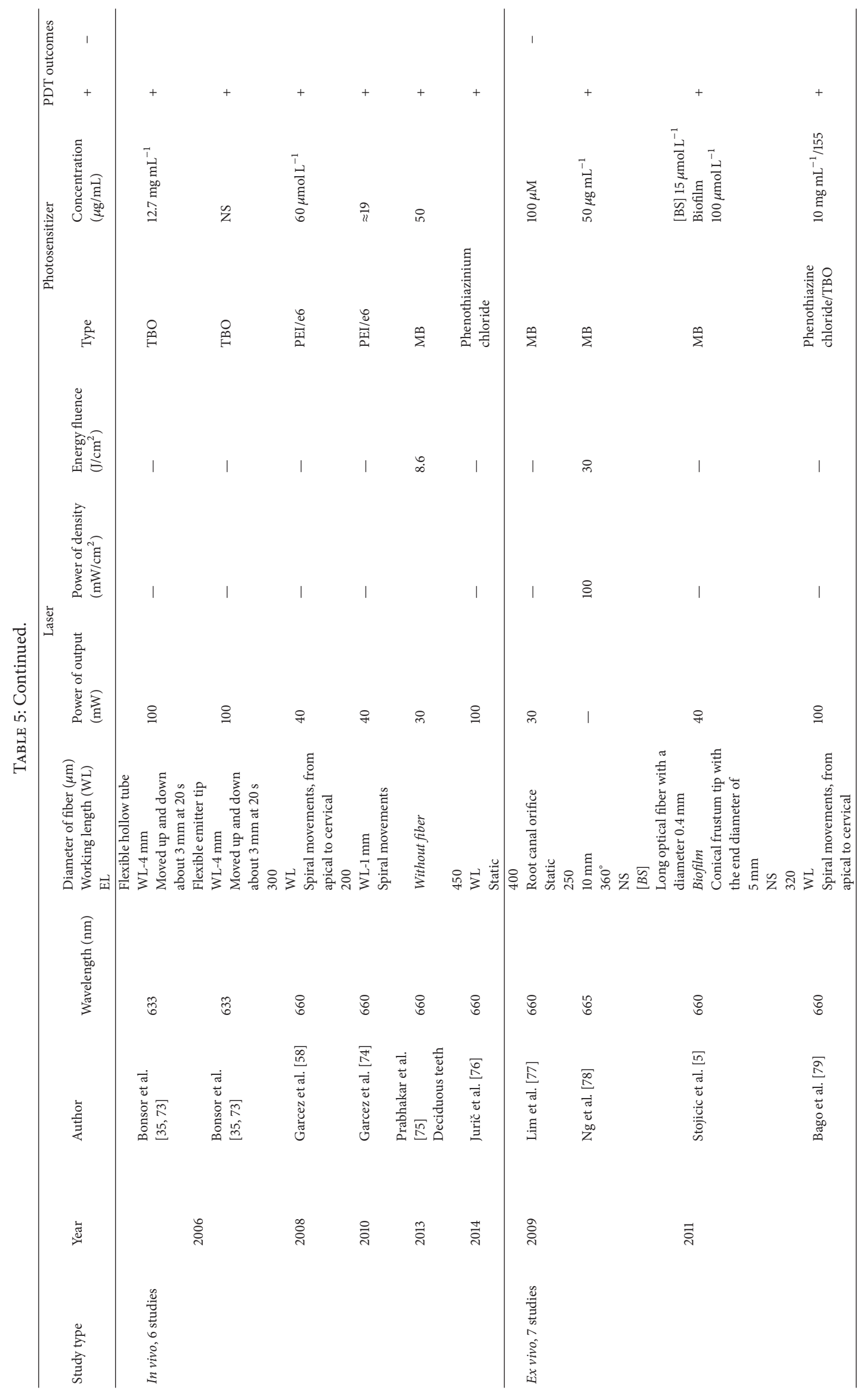




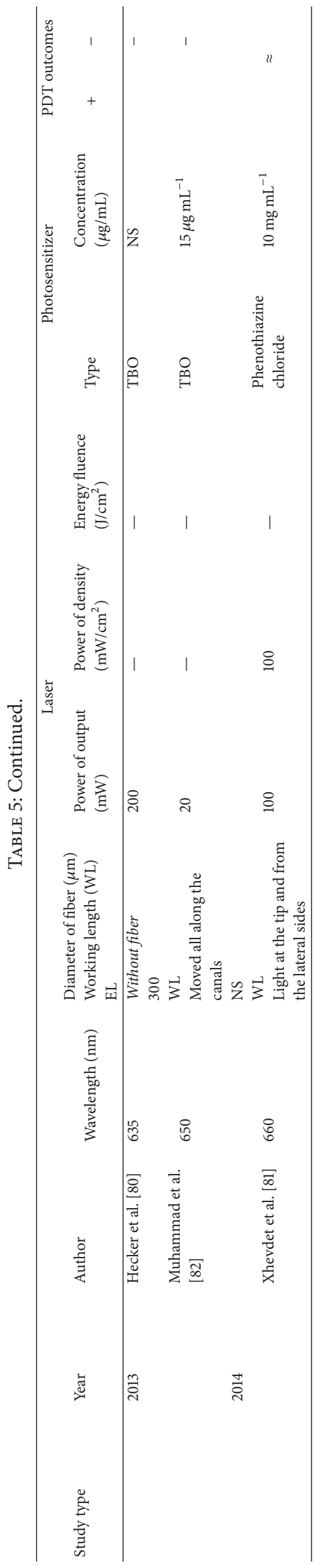


is the classical irrigant most used in endodontic therapy as a powerful antibacterial organic tissue dissolving agent.

$\mathrm{NaOCl}$ penetrates to a depth of approximately $130 \mu \mathrm{m}$ [92] to $160 \mu \mathrm{m}$ into dentinal tubules whereas tubular infection may occur closer to cementum-dentin junction (up to $1000 \mu \mathrm{m}$ ) [93]. Bumb et al. [61] demonstrated in scanning electron microscope (SEM) penetration up to $1000 \mu \mathrm{m}$ into dentinal tubules of E. faecalis and compared penetrating power between a high power laser (Nd:YAG) that can go to a range of $400-850 \mu \mathrm{m}$ and PDT group that reaches as deep as $890-900 \mu \mathrm{m}$.

Considering $\mathrm{NaOCl}$ as an unquestionable irrigation solution, its universal effective minimal concentration remains unclear. Apart from various outcomes reported by previous studies on comparative effectiveness of hypochlorite at different concentrations, it is regularly accepted that effectiveness of $\mathrm{NaOCl}$ is proportional to its concentration [24, 72, 94]. In antimicrobial PDT studies, $\mathrm{NaOCl}$ concentration range is between $0.5[57,67,75,80]$ and $6 \%[68,78]$ and mainstream of studies used $2.5 \% \mathrm{NaOCl}$ concentration $[34,58,62,64,65,70$, $71,74,76,79,81]$. Due to the fact that $\mathrm{NaOCl}$ has an influence upon only organic components of SL, it should be used with demineralizing agents, which can remove inorganic component of smear layer. Concerning SL elimination, only 3 readings $[35,70,73]$ reported citric acid as a SL deletion, one at $10 \%$ [70] and two at $20 \%$ from the same author, Bonsor et al. $[35,73]$. But the most popular SL removal is by far $17 \%$ ethylenediamine tetraacetic acid (EDTA) $[34,57-$ $59,61,63,65-69,71,74,76-78,81,82]$.

3.7. Microorganisms. Reviewing literature on use of several microorganisms in PDT studies, authors could not evaluate in vivo studies in those terms, because no attempt was made to identify bacterial flora during culture process $[35,58,73,75]$ in four of six studies. Only Garcez et al., 2010 [74], and Jurič et al., 2014 [76], established microbiological identification.

Among all studies, we analysed 23 studies (all in vitro and ex vivo), and from those, 20 (87\%) elected Enterococcus faecalis as substract to quantify antimicrobial PDT effectiveness. E. faecalis is a Gram-positive facultative anaerobe commonly detected in asymptomatic, persistent endodontic infections. Its prevalence in such infections ranges from $24 \%$ to $77 \%$ [95]. This finding can be explained by various survival and virulence factors [95] expressed by E. faecalis, including its ability to compete with other microorganisms, invade dentinal tubules, and resist nutritional deprivation.

E. faecalis was used not only in planktonic suspensions, but also in form of biofilms and the most common strain selected was ATCC29212. However, biofilm maturation time did not follow a linear pattern; besides, a huge discrepancy exists. Some authors used young biofilms with range of 2 $[60,68], 4[60]$, and 7 days $[81,82]$ very distinct from mature biofilms performed with biofilms of $21[61,66], 28[5,69,72$, 77], and 70 days [59]. According to Kishen and Haapasalo 2010 [12], a mature biofilm is considered when maturation period is equal to or higher than 21 days and only 7 (30\%) studies $[5,59,61,66,69,72,77]$ respected this mature biofilm criteria. Apart from E. faecalis, other microorganisms were reviewed. Of note, in literature, the first PDT in vitro study was performed by Seal et al. 2002 [63] in root canals infected with Streptococcus intermedius (Gram-positive facultative anaerobe) biofilm with 2 days of maturation using TBO as PS and a helium-neon laser as light source.

\section{Discussion}

PDT, a technique with potentially significant antimicrobial properties, is a fairly recent approach in endodontic disinfection protocols. While the oral applications of PDT have been extensively tested, variations in study type and design limits the ability to synthesize or pool the available quantitative data, thereby permitting a formal meta-analysis and a systematic review.

Furthermore, many of the studies quantitatively measuring the degree of bacterial kill fail to report baseline bacterial counts or concentrations, thus limiting the ability to assess the bactericidal efficacy of PDT. Considering this apparent variation in reporting results among the studies analysed, it is difficult to provide a definitive assessment of the research question posed in this review. It is important to mention that PDT efficacy is shown in CFU or in percentage and logarithm (in form of $\log _{10}$ ); nonetheless, authors state this is pointless without the perception of the initial concentration. As an example, if we have an initial sample from a root canal of $10^{7}$ microorganisms and if after PDT approach we had $10^{5}$, statistically, 99\% were killed, but there are still 100000 microorganisms left inside the root canal. Considering the variation in units at outcomes, the final results analysis is difficult.

Even though PDT has significant advantages (cited in Section 1), potential adverse events as tooth discoloration have been reported previously in root canal treatment when $\mathrm{MB}$ and TBO were used as PS [96]. It is also important that future clinical studies clearly report adverse events associated with PDT so that an estimation of the benefit-to-risk ratio from the use of PDT is feasible. Nonetheless, there were no adverse effects mentioned in the included studies of the current review.

PDT outcomes in literature have been reported by the dual combination of PS and a visible light source in the presence of oxygen; however, recently, Lins de Sousa et al. [97] analysed that twice-daily blue light of $420 \mathrm{~nm}$, energy density of $72 \mathrm{Jcm}^{-2}$, and irradiation time of $776 \mathrm{~s}$ without PS are a promising approach in the inhibition of five days' Streptococcus mutans matrix-rich biofilm development. It has remarkably inhibited the production of insoluble EPS, which is responsible for the scaffold of the extracellular biofilm matrix. The authors suggest that this evidence is very important to improve standardization in PDT procedures in the total absence of light as the evaluation of PS dark toxicity in some studies reviewed did not address this important issue.

In the literature, residual systemic photosensitization has also been reported as a potentially adverse event associated with the use of intravenous PS [98]; but this effect appears to not be associated with oral applications of PDT [99]. The role of PDT in root canal disinfection has been tested using several combinations of PS and light sources and has shown divergent results and these studies have revealed several limitations associated with antimicrobial PDT. For successful 
PDT to affect significant reduction or eradication of microorganisms, a PS is required which will show enough affinity for microorganisms without catalyzing photodamage to host tissues, a light source at a wavelength that can penetrate tissues (630-700 nm), and sufficient oxygenation to produce a level of reactive oxygen species (ROS) necessary to induce photodynamic lipid peroxidation and, as a consequence, necrosis and cell death. If there is photodamage to both tissues and microorganisms, efficacy will be suboptimal.

Microorganisms in the root canal flora and their growth mode were found to influence their susceptibility to PDT in a dose-dependent manner [100] and biofilms can be difficult to eradicate not only because of their effect as barriers to PS uptake, but also their ability to diffuse or attenuate light in the root canal dentinal tubules. Even dentin, dentin matrix, pulp tissue, bacterial lipopolysaccharides, and bovine serum albumin were found to significantly decrease PDT antimicrobial efficacy [101] and, as a consequence, an effort to enhance the PDT by nanoparticle-based technology appears promising [102]. Other strategies include the use of a PS solvent [103], efflux pump inhibitors [100], or photoactivated functionalized chitosan nanoparticles for disinfection and stabilization of the dentin matrix [104]. Because the application of PDT for additional reduction of the microbial load of root canal systems seems promising, it would be beneficial to identify the ideal combination of PS and light wavelength in preclinical studies and conduct future randomized controlled trials to test the effect of PDT on root canal disinfection in various indications.

\section{Conclusion}

PDT has been used thus far without a consensus-based, welldefined protocol, and therefore still remains at an experimental stage waiting for further optimization. Limited clinical information is currently available on the use of PDT in root canal disinfection. Currently, the level of evidence of available clinical studies to answer this question is low. Nevertheless, the results of this review suggest, based primarily on available in vivo studies, that PDT could perform well as an antimicrobial adjuvant. PDT appears to be a promising antimicrobial platform so further studies are warranted to optimize protocols using standardized laser and PS parameters to assess the PDT efficacy. Therefore, within the limits of the present review, one may conclude that the efficacy of PDT remains questionable, but promising. It is further suggested that an additional potential benefit from the use of PDT in root canal disinfection may exist where highly resistant bacteria are present in the root canal space, thus affecting the treatment prognosis. Further research is necessary to establish the appropriate PDT parameters allowing adequate antimicrobial action without harmful host side effects.

\section{Conflict of Interests}

The authors declare that there is no conflict of interests regarding the publication of this paper.

\section{References}

[1] S. Friedman, "Considerations and concepts of case selection in the management of post-treatment endodontic disease (treatment failure)," Endodontic Topics, vol. 1, no. 1, pp. 54-78, 2002.

[2] U. Sjögren, D. Figdor, S. Persson, and G. Sundqvist, "Influence of infection at the time of root filling on the outcome of endodontic treatment of teeth with apical periodontitis," International Endodontic Journal, vol. 30, no. 5, pp. 297-306, 1997.

[3] T. Waltimo, M. Trope, M. Haapasalo, and D. Ørstavik, "Clinical efficacy of treatment procedures in endodontic infection control and one year follow-up of periapical healing," Journal of Endodontics, vol. 31, no. 12, pp. 863-866, 2005.

[4] J. F. Siqueira Jr., M. C. Araújo, P. F. Garcia, R. C. Fraga, and C. J. Dantas, "Histological evaluation of the effectiveness of five instrumentation techniques for cleaning the apical third of root canals," Journal of Endodontics, vol. 23, no. 8, pp. 499-502, 1997.

[5] S. Stojicic, H. Amorim, Y. Shen, and M. Haapasalo, "Ex vivo killing of Enterococcus faecalis and mixed plaque bacteria in planktonic and biofilm culture by modified photoactivated disinfection," International Endodontic Journal, vol. 46, no. 7, pp. 649-659, 2013.

[6] Y.-G. Qiang, C. M. N. Yow, and Z. Huang, "Combination of photodynamic therapy and immunomodulation: current status and future trends," Medicinal Research Reviews, vol. 28, no. 4, pp. 632-644, 2008.

[7] L. C. De Paz, "Redefining the persistent infection in root canals: possible role of biofilm communities," Journal of Endodontics, vol. 33, no. 6, pp. 652-662, 2007.

[8] J. W. Costerton, K. J. Cheng, G. G. Geesey et al., "Bacterial biofilms in nature and disease," Annual Review of Microbiology, vol. 41, pp. 435-464, 1987.

[9] G. Svensäter, B. Sjögreen, and I. R. Hamilton, "Multiple stress responses in Streptococcus mutans and the induction of general and stress-specific proteins," Microbiology, vol. 146, no. 1, pp. 107-117, 2000.

[10] K. Lewis, "Persister cells and the riddle of biofilm survival," Biochemistry, vol. 70, no. 2, pp. 267-274, 2005.

[11] G. H. W. Bowden and I. R. Hamilton, "Survival of oral bacteria," Critical Reviews in Oral Biology \& Medicine, vol. 9, no. 1, pp. 5485, 1998.

[12] A. Kishen and M. Haapasalo, "Biofilm models and methods of biofilm assessment," Endodontic Topics, vol. 22, no. 1, pp. 58-78, 2010.

[13] G. Svensater and G. Bergenholtz, "Biofilms in endodontic infections," Endodontic Topics, vol. 9, no. 1, pp. 27-36, 2004.

[14] M. Zehnder, "Root Canal Irrigants," Journal of Endodontics, vol. 32, no. 5, pp. 389-398, 2006.

[15] J. M. Santos, P. J. Palma, J. C. Ramos, A. S. Cabrita, and S. Friedman, "Periapical inflammation subsequent to coronal inoculation of dog teeth root filled with Resilon/Epiphany in 1 or 2 treatment sessions with chlorhexidine medication," Journal of Endodontics, vol. 40, no. 6, pp. 837-841, 2014.

[16] A. Bystrom, R. Claesson, and G. Sundqvist, "The antibacterial effect of camphorated paramonochlorophenol, camphorated phenol and calcium hydroxide in the treatment of infected root canals," Endodontics \& Dental Traumatology, vol. 1, no. 5, pp. 170-175, 1985.

[17] J. F. Siqueira Jr., T. Guimarães-Pinto, and I. N. Rôças, “Effects of chemomechanical preparation with $2.5 \%$ sodium hypochlorite and intracanal medication with calcium hydroxide on cultivable 
bacteria in infected root canals," Journal of Endodontics, vol. 33, no. 7, pp. 800-805, 2007.

[18] R. D. Morgental, A. Singh, H. Sappal, P. M. P. Kopper, F. V. Vier-Pelisser, and O. A. Peters, "Dentin inhibits the antibacterial effect of new and conventional endodontic irrigants," Journal of Endodontics, vol. 39, no. 3, pp. 406-410, 2013.

[19] I. Portenier, H. Haapasalo, A. Rye, T. Waltimo, D. Ørstavik, and M. Haapasalo, "Inactivation of root canal medicaments by dentine, hydroxylapatite and bovine serum albumin," International Endodontic Journal, vol. 34, no. 3, pp. 184-188, 2001.

[20] M. Evans, J. K. Davies, G. Sundqvist, and D. Figdor, "Mechanisms involved in the resistance of Enterococcus faecalis to calcium hydroxide," International Endodontic Journal, vol. 35, no. 3, pp. 221-228, 2002.

[21] W. L. Chai, H. Hamimah, S. C. Cheng, A. A. Sallam, and M. Abdullah, "Susceptibility of Enterococcus faecalis biofilm to antibiotics and calcium hydroxide," Journal of Oral Science, vol. 49, no. 2, pp. 161-166, 2007.

[22] T. M. T. Waltimo, E. K. Sirén, H. L. K. Torkko, I. Olsen, and M. P. P. Haapasalo, "Fungi in therapy-resistant apical periodontitis," International Endodontic Journal, vol. 30, no. 2, pp. 96-101, 1997.

[23] M. A. Al-Fattani and L. J. Douglas, "Biofilm matrix of Candida albicans and Candida tropicalis: chemical composition and role in drug resistance," Journal of Medical Microbiology, vol. 55, no. 8, pp. 999-1008, 2006.

[24] J. F. Siqueira Jr. and I. N. Rôças, "Clinical implications and microbiology of bacterial persistence after treatment procedures," Journal of Endodontics, vol. 34, no. 11, pp. 1291-1301, 2008.

[25] A. Kuştarci, Z. Sümer, D. Altunbaş, and S. Koşum, "Bactericidal effect of KTP laser irradiation against Enterococcus faecalis compared with gaseous ozone: an ex vivo study," Oral Surgery, Oral Medicine, Oral Pathology, Oral Radiology and Endodontology, vol. 107, no. 5, pp. e73-e79, 2009.

[26] C. Heilborn, K. Reynolds, J. D. Johnson, and N. Cohenca, "Cleaning efficacy of an apical negative-pressure irrigation system at different exposure times.," Quintessence International, vol. 41, no. 9, pp. 759-767, 2010.

[27] R. J. G. De Moor, M. Meire, K. Goharkhay, A. Moritz, and J. Vanobbergen, "Efficacy of ultrasonic versus laser-activated irrigation to remove artificially placed dentin debris plugs," Journal of Endodontics, vol. 36, no. 9, pp. 1580-1583, 2010.

[28] A. Halford, C.-D. Ohl, A. Azarpazhooh, B. Basrani, S. Friedman, and A. Kishen, "Synergistic effect of microbubble emulsion and sonic or ultrasonic agitation on endodontic biofilm in vitro," Journal of Endodontics, vol. 38, no. 11, pp. 1530-1534, 2012.

[29] R. G. Macedo, B. Verhaagen, D. F. Rivas, M. Versluis, P. Wesselink, and L. van der Sluis, "Cavitation measurement during sonic and ultrasonic activated irrigation," Journal of Endodontics, vol. 40, no. 4, pp. 580-583, 2014.

[30] A. Shrestha, S. Zhilong, N. K. Gee, and A. Kishen, "Nanoparticulates for antibiofilm treatment and effect of aging on its antibacterial activity," Journal of Endodontics, vol. 36, no. 6, pp. 1030-1035, 2010.

[31] M. Kvist, V. Hancock, and P. Klemm, "Inactivation of efflux pumps abolishes bacterial biofilm formation," Applied and Environmental Microbiology, vol. 74, no. 23, pp. 7376-7382, 2008.

[32] B. W. Henderson and T. J. Dougherty, "How does photodynamic therapy work?" Photochemistry and Photobiology, vol. 55, no. 1, pp. 145-157, 1992.
[33] M. Wainwright, "Photodynamic antimicrobial chemotherapy (PACT)," Journal of Antimicrobial Chemotherapy, vol. 42, no. 1, pp. 13-28, 1998.

[34] A. S. Garcez, M. S. Ribeiro, G. P. Tegos, S. C. Núñez, A. O. C. Jorge, and M. R. Hamblin, "Antimicrobial photodynamic therapy combined with conventional endodontic treatment to eliminate root canal biofilm infection," Lasers in Surgery and Medicine, vol. 39, no. 1, pp. 59-66, 2007.

[35] S. J. Bonsor, R. Nichol, T. M. S. Reid, and G. J. Pearson, "Microbiological evaluation of photo-activated disinfection in endodontics (an in vivo study)," British Dental Journal, vol. 200, no. 6, pp. 337-341, 2006.

[36] M. R. Hamblin and T. Hasan, "Photodynamic therapy: a new antimicrobial approach to infectious disease?" Photochemical and Photobiological Sciences, vol. 3, no. 5, pp. 436-450, 2004.

[37] A. P. Castano, T. N. Demidova, and M. R. Hamblin, "Mechanisms in photodynamic therapy: part one-photosensitizers, photochemistry and cellular localization," Photodiagnosis and Photodynamic Therapy, vol. 1, no. 4, pp. 279-293, 2004.

[38] A. C. Trindade, J. A. P. De Figueiredo, L. Steier, and J. B. B. Weber, "Photodynamic therapy in endodontics: a literature review," Photomedicine and Laser Surgery, vol. 33, no. 3, pp. 175182, 2015.

[39] T. Dai, Y.-Y. Huang, and M. R. Hamblin, "Photodynamic therapy for localized infections-state of the art," Photodiagnosis and Photodynamic Therapy, vol. 6, no. 3-4, pp. 170-188, 2009.

[40] A. Minnock, D. I. Vernon, J. Schofield, J. Griffiths, J. H. Parish, and S. B. Brown, "Mechanism of uptake of a cationic watersoluble pyridinium zinc phthalocyanine across the outer membrane of Escherichia coli," Antimicrobial Agents and Chemotherapy, vol. 44, no. 3, pp. 522-527, 2000.

[41] S. George, M. R. Hamblin, and A. Kishen, "Uptake pathways of anionic and cationic photosensitizers into bacteria," Photochemical and Photobiological Sciences, vol. 8, no. 6, pp. 788-795, 2009.

[42] J. P. Tardivo, A. Del Giglio, C. S. De Oliveira et al., "Methylene blue in photodynamic therapy: from basic mechanisms to clinical applications," Photodiagnosis and Photodynamic Therapy, vol. 2, no. 3, pp. 175-191, 2005.

[43] Y. R. Kim, S. Kim, J. W. Choi et al., "Bioluminescence-activated deep-tissue photodynamic therapy of cancer," Theranostics, vol. 5, no. 8, pp. 805-817, 2015.

[44] T. J. Dougherty, C. J. Gomer, B. W. Henderson et al., "Photodynamic therapy," Journal of the National Cancer Institute, vol. 90, no. 12, pp. 889-905, 1998.

[45] N. S. Soukos, P. S.-Y. Chen, J. T. Morris et al., "Photodynamic therapy for endodontic disinfection," Journal of Endodontics, vol. 32, no. 10, pp. 979-984, 2006.

[46] M. Wainwright, "Local treatment of viral disease using photodynamic therapy," International Journal of Antimicrobial Agents, vol. 21, no. 6, pp. 510-520, 2003.

[47] J. M. Bliss, C. E. Bigelow, T. H. Foster, and C. G. Haidaris, "Susceptibility of Candida species to photodynamic effects of Photofrin," Antimicrobial Agents and Chemotherapy, vol. 48, no. 6, pp. 2000-2006, 2004.

[48] A. Azarpazhooh, P. S. Shah, H. C. Tenenbaum, and M. B. Goldberg, "The effect of photodynamic therapy for periodontitis: a systematic review and meta-analysis," Journal of Periodontology, vol. 81, no. 1, pp. 4-14, 2010.

[49] F. Vohra, M. Q. Al-Rifaiy, G. Lillywhite, M. I. Abu Hassan, and F. Javed, "Efficacy of mechanical debridement with adjunct 
antimicrobial photodynamic therapy for the management of peri-implant diseases: a systematic review," Photochemical and Photobiological Sciences, vol. 13, no. 8, pp. 1160-1168, 2014.

[50] A. A. Takasaki, A. Aoki, K. Mizutani et al., "Application of antimicrobial photodynamic therapy in periodontal and periimplant diseases," Periodontology 2000, vol. 51, no. 1, pp. 109$140,2009$.

[51] H. Gursoy, C. Ozcakir-Tomruk, J. Tanalp, and S. Yilmaz, "Photodynamic therapy in dentistry: a literature review," Clinical Oral Investigations, vol. 17, no. 4, pp. 1113-1125, 2013.

[52] S. H. Siddiqui, K. H. Awan, and F. Javed, "Bactericidal efficacy of photodynamic therapy against Enterococcus faecalis in infected root canals: a systematic literature review," Photodiagnosis and Photodynamic Therapy, vol. 10, no. 4, pp. 632-643, 2013.

[53] V. Chrepa, G. A. Kotsakis, T. C. Pagonis, and K. M. Hargreaves, "The effect of photodynamic therapy in root canal disinfection: a systematic review," Journal of Endodontics, vol. 40, no. 7, pp. 891-898, 2014.

[54] B. N. Green, C. D. Johnson, and A. Adams, "Writing narrative literature reviews for peer-reviewed journals: secrets of the trade," Journal of Chiropractic Medicine, vol. 5, no. 3, pp. 101-117, 2006.

[55] V. Elm, D. G. Altman, M. Egger, S. J. Pocock, C. Gøtzsche, and J. P. Vandenbroucke, "The strengthening the reporting of observational studies in epidemiology (STROBE) statement: guidelines for reporting observational studies," The British Medical Journal, vol. 335, no. 7624, pp. 806-808, 2033.

[56] P. Jüni, D. G. Altman, and M. Egger, "Assessing the quality of controlled clinical trials," The BMJ, vol. 323 , no. 7, pp. 42-46, 2001.

[57] A. Silva Garcez, S. C. Núñez, J. L. Lage-Marques, A. O. C. Jorge, and M. S. Ribeiro, "Efficiency of $\mathrm{NaOCl}$ and laser-assisted photosensitization on the reduction of Enterococcus faecalis in vitro," Oral Surgery, Oral Medicine, Oral Pathology, Oral Radiology and Endodontology, vol. 102, no. 4, pp. 93-98, 2006.

[58] A. S. Garcez, S. C. Nuñez, M. R. Hamblin, and M. S. Ribeiro, "Antimicrobial effects of photodynamic therapy on patients with necrotic pulps and periapical lesion," Journal of Endodontics, vol. 34, no. 2, pp. 138-142, 2008.

[59] S. George and A. Kishen, "Augmenting the antibiofilm efficacy of advanced noninvasive light activated disinfection with emulsified oxidizer and oxygen carrier," Journal of Endodontics, vol. 34, no. 9, pp. 1119-1123, 2008.

[60] G. Pileggi, J. C. Wataha, M. Girard et al., "Blue light-mediated inactivation of Enterococcus faecalis in vitro," Photodiagnosis and Photodynamic Therapy, vol. 10, no. 2, pp. 134-140, 2013.

[61] S. Bumb, D. Bhaskar, C. Agali et al., "Assessment of photodynamic therapy (PDT) in disinfection of deeper dentinal tubules in a root canal system: an in vitro study," Journal of Clinical and Diagnostic Research, vol. 8, no. 11, pp. 67-71, 2014.

[62] M. Nagayoshi, T. Nishihara, K. Nakashima et al., "Bactericidal effects of diode laser irradiation on Enterococcus faecalis using periapical lesion defect model," ISRN Dentistry, vol. 2011, Article ID 870364, 6 pages, 2011.

[63] G. J. Seal, Y.-L. Ng, D. Spratt, M. Bhatti, and K. Gulabivala, "An in vitro comparison of the bactericidal efficacy of lethal photosensitization or sodium hyphochlorite irrigation on Streptococcus intermedius biofilms in root canals," International Endodontic Journal, vol. 35, no. 3, pp. 268-274, 2002.

[64] M. A. Meire, K. De Prijck, T. Coenye, H. J. Nelis, and R. J. G. De Moor, "Effectiveness of different laser systems to kill
Enterococcus faecalis in aqueous suspension and in an infected tooth model," International Endodontic Journal, vol. 42, no. 4, pp. 351-359, 2009.

[65] L. C. Souza, P. R. R. Brito, J. C. Machado de Oliveira et al., "Photodynamic therapy with two different photosensitizers as a supplement to instrumentation/irrigation procedures in promoting intracanal reduction of Enterococcus faecalis," Journal of Endodontics, vol. 36, no. 2, pp. 292-296, 2010.

[66] M. R. Nunes, I. Mello, G. C. N. Franco et al., "Effectiveness of photodynamic therapy against Enterococcus faecalis, with and without the use of an intracanal optical fiber: an in vitro study," Photomedicine and Laser Surgery, vol. 29, no. 12, pp. 803-808, 2011.

[67] C. Poggio, C. R. Arciola, A. Dagna et al., "Photoactivated disinfection (PAD) in endodontics: an in vitro microbiological evaluation," International Journal of Artificial Organs, vol. 34, no. 9, pp. 889-897, 2011.

[68] A. Rios, J. He, G. N. Glickman, R. Spears, E. D. Schneiderman, and A. L. Honeyman, "Evaluation of photodynamic therapy using a light-emitting diode lamp against enterococcus faecalis in extracted human teeth," Journal of Endodontics, vol. 37, no. 6, pp. 856-859, 2011.

[69] X. Cheng, S. Guan, H. Lu et al., "Evaluation of the bactericidal effect of Nd:YAG, Er:YAG, Er,Cr:YSGG laser radiation, and antimicrobial photodynamic therapy (aPDT) in experimentally infected root canals," Lasers in Surgery and Medicine, vol. 44, no. 10, pp. 824-831, 2012.

[70] S. Vaziri, A. Kangarlou, R. Shahbazi, A. Nazari Nasab, and M. Naseri, "Comparison of the bactericidal efficacy of photodynamic therapy, $2.5 \%$ sodium hypochlorite, and $2 \%$ chlorhexidine against Enterococcous faecalis in root canals; an in vitro study," Dental Research Journal, vol. 9, no. 5, pp. 613-618, 2012.

[71] R. T. Gergova, T. Gueorgieva, M. S. Dencheva-Garova et al., "Antimicrobial activity of different disinfection methods against biofilms in root canals," Journal of Investigative and Clinical Dentistry, 2015.

[72] Y. Wang, S. Xiao, D. Ma, X. Huang, and Z. Cai, "Minimizing concentration of sodium hypochlorite in root canal irrigation by combination of ultrasonic irrigation with photodynamic treatment," Photochemistry and Photobiology, vol. 91, no. 4, pp. 937-941, 2015.

[73] S. J. Bonsor, R. Nichol, T. M. S. Reid, and G. J. Pearson, "An alternative regimen for root canal disinfection," British Dental Journal, vol. 201, no. 2, pp. 101-105, 2006.

[74] A. S. Garcez, S. C. Nuñez, M. R. Hamblim, H. Suzuki, and M. S. Ribeiro, "Photodynamic therapy associated with conventional endodontic treatment in patients with antibiotic-resistant microflora: a preliminary report," Journal of Endodontics, vol. 36, no. 9, pp. 1463-1466, 2010.

[75] A. Prabhakar, C. Yavagal, S. Agarwal, N. Basappa, and S. Pradhan, "Antimicrobial effects of laser-assisted photodynamic therapy in pediatric endodontic treatment: a new clinical horizon," International Journal of Laser Dentistry, vol. 3, no. 3, pp. 77-81, 2013.

[76] I. B. Jurič, V. Plečko, D. G. Pandurić, and I. Anić, "The antimicrobial effectiveness of photodynamic therapy used as an addition to the conventional endodontic re-treatment: a clinical study," Photodiagnosis and Photodynamic Therapy, vol. 11, no. 4, pp. 549-555, 2014.

[77] Z. Lim, J. L. Cheng, T. W. Lim et al., "Light activated disinfection: an alternative endodontic disinfection strategy," Australian Dental Journal, vol. 54, no. 2, pp. 108-114, 2009. 
[78] R. Ng, F. Singh, D. A. Papamanou et al., "Endodontic photodynamic therapy ex vivo," Journal of Endodontics, vol. 37, no. 2, pp. 217-222, 2011.

[79] I. Bago, V. Plečko, D. G. Pandurić, Z. Schauperl, A. Baraba, and I. Anić, "Antimicrobial efficacy of a high-power diode laser, photo-activated disinfection, conventional and sonic activated irrigation during root canal treatment," International Endodontic Journal, vol. 46, no. 4, pp. 339-347, 2013.

[80] S. Hecker, K.-A. Hiller, K. M. Galler, S. Erb, T. Mader, and G. Schmalz, "Establishment of an optimized ex vivo system for artificial root canal infection evaluated by use of sodium hypochlorite and the photodynamic therapy," International Endodontic Journal, vol. 46, no. 5, pp. 449-457, 2013.

[81] A. Xhevdet, D. Stubljar, I. Kriznar et al., "The disinfecting efficacy of root canals with laser photodynamic therapy," Journal of Lasers in Medical Sciences, vol. 5, no. 1, pp. 19-26, 2014.

[82] O. H. Muhammad, M. Chevalier, J.-P. Rocca, N. BrulatBouchard, and E. Medioni, "Photodynamic therapy versus ultrasonic irrigation: interaction with endodontic microbial biofilm, an ex vivo study," Photodiagnosis and Photodynamic Therapy, vol. 11, no. 2, pp. 171-181, 2014.

[83] S. George, A. Kishen, and K. P. Song, "The role of environmental changes on monospecies biofilm formation on root canal wall by Enterococcus faecalis," Journal of Endodontics, vol. 31, no. 12, pp. 867-872, 2005.

[84] L. Bergmans, P. Moisiadis, W. Teughels, B. Van Meerbeek, M. Quirynen, and P. Lambrechts, "Bactericidal effect of Nd:YAG laser irradiation on some endodontic pathogens ex vivo," International Endodontic Journal, vol. 39, no. 7, pp. 547-557, 2006.

[85] M. Wainwright, "The development of phenothiazinium photosensitisers," Photodiagnosis and Photodynamic Therapy, vol. 2, no. 4, pp. 263-272, 2005.

[86] M. Wainwright, D. A. Phoenix, J. Marland, D. R. A. Wareing, and F. J. Bolton, "A study of photobactericidal activity in the phenothiazinium series," FEMS Immunology and Medical Microbiology, vol. 19, no. 1, pp. 75-80, 1997.

[87] Z. Wang, Y. Shen, and M. Haapasalo, "Effectiveness of endodontic disinfecting solutions against young and old Enterococcus faecalis biofilms in dentin canals," Journal of Endodontics, vol. 38, no. 10, pp. 1376-1379, 2012.

[88] P. F. C. Menezes, C. A. S. Melo, V. S. Bagnato, H. Imasato, and J. R. Perussi, "Dark cytotoxicity of the photoproducts of the photosensitizer photogem after photobleaching induced by a laser," Laser Physics, vol. 15, no. 3, pp. 435-442, 2005.

[89] R. Ackroyd, C. Kelty, N. Brown, and M. Reed, "The history of photodetection and photodynamic therapy," Photochemistry and Photobiology, vol. 74, no. 5, pp. 656-669, 2001.

[90] L. Bergmans, P. Moisiadis, B. Huybrechts, B. Van Meerbeek, M. Quirynen, and P. Lambrechts, "Effect of photo-activated disinfection on endodontic pathogens ex vivo," International Endodontic Journal, vol. 41, no. 3, pp. 227-239, 2008.

[91] M. A. Meire, T. Coenye, H. J. Nelis, and R. J. G. De Moor, "Evaluation of Nd: YAG and Er: YAG irradiation, antibacterial photodynamic therapy and sodium hypochlorite treatment on Enterococcus faecalis biofilms," International Endodontic Journal, vol. 45, no. 5, pp. 482-491, 2012.

[92] E. Berutti, R. Marini, and A. Angeretti, "Penetration ability of different irrigants into dentinal tubules," Journal of Endodontics, vol. 23, no. 12, pp. 725-727, 1997.

[93] L. B. Peters, P. R. Wesselink, J. F. Buijs, and A. J. Van Winkelhoff, "Viable bacteria in root dentinal tubules of teeth with apical periodontitis," Journal of Endodontics, vol. 27, no. 2, pp. 76-81, 2001.

[94] B. P. F. A. Gomes, C. C. R. Ferraz, M. E. Vianna, V. B. Berber, F. B. Teixeira, and F. J. de Souza-Filho, "In vitro antimicrobial activity of several concentrations of sodium hypochlorite and chlorhexidine gluconate in the elimination of Enterococcus faecalis," International Endodontic Journal, vol. 34, no. 6, pp. 424-428, 2001.

[95] C. H. Stuart, S. A. Schwartz, T. J. Beeson, and C. B. Owatz, "Enterococcus faecalis: its role in root canal treatment failure and current concepts in retreatment," Journal of Endodontics, vol. 32, no. 2, pp. 93-98, 2006.

[96] R. A. Figueiredo, L. C. Anami, I. Mello, E. D. S. Carvalho, S. M. Habitante, and D. P. Raldi, "Tooth discoloration induced by endodontic phenothiazine dyes in photodynamic therapy," Photomedicine and Laser Surgery, vol. 32, no. 8, pp. 458-462, 2014.

[97] D. Lins de Sousa, R. Araújo Lima, I. C. Zanin et al., "Effect of twice-daily blue Light treatment on matrix-rich biofilm development," PLoS ONE, vol. 10, no. 7, Article ID e0131941, 2015.

[98] K. Konopka and T. Goslinski, "Photodynamic therapy in dentistry," Journal of Dental Research, vol. 86, no. 8, pp. 694-707, 2007.

[99] M. Wilson, "Lethal photosensitisation of oral bacteria and its potential application in the photodynamic therapy of oral infections," Photochemical and Photobiological Sciences, vol. 3, no. 5, pp. 412-418, 2004.

[100] M. H. Upadya and A. Kishen, "Influence of bacterial growth modes on the susceptibility to light-activated disinfection," International Endodontic Journal, vol. 43, no. 11, pp. 978-987, 2010.

[101] A. Shrestha and A. Kishen, "The effect of tissue inhibitors on the antibacterial activity of chitosan nanoparticles and photodynamic therapy," Journal of Endodontics, vol. 38, no. 9, pp. 1275-1278, 2012.

[102] T. C. Pagonis, J. Chen, C. R. Fontana et al., "Nanoparticle-based endodontic antimicrobial photodynamic therapy," Journal of Endodontics, vol. 36, no. 2, pp. 322-328, 2010.

[103] S. George and A. Kishen, "Influence of photosensitizer solvent on the mechanisms of photoactivated killing of Enterococcus faecalis," Photochemistry and Photobiology, vol. 84, no. 3, pp. 734-740, 2008.

[104] A. Shrestha, M. R. Hamblin, and A. Kishen, "Photoactivated rose bengal functionalized chitosan nanoparticles produce antibacterial/biofilm activity and stabilize dentin-collagen," Nanomedicine: Nanotechnology, Biology, and Medicine, vol. 10, no. 3, pp. 491-501, 2014. 


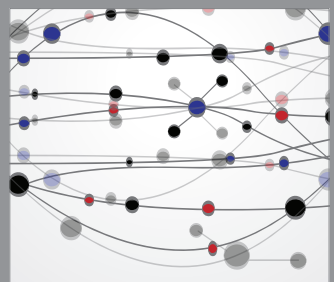

The Scientific World Journal
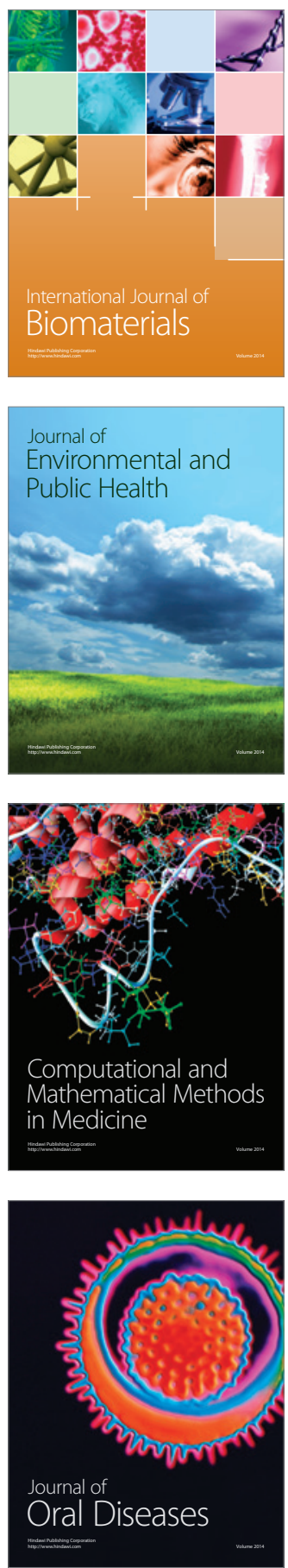
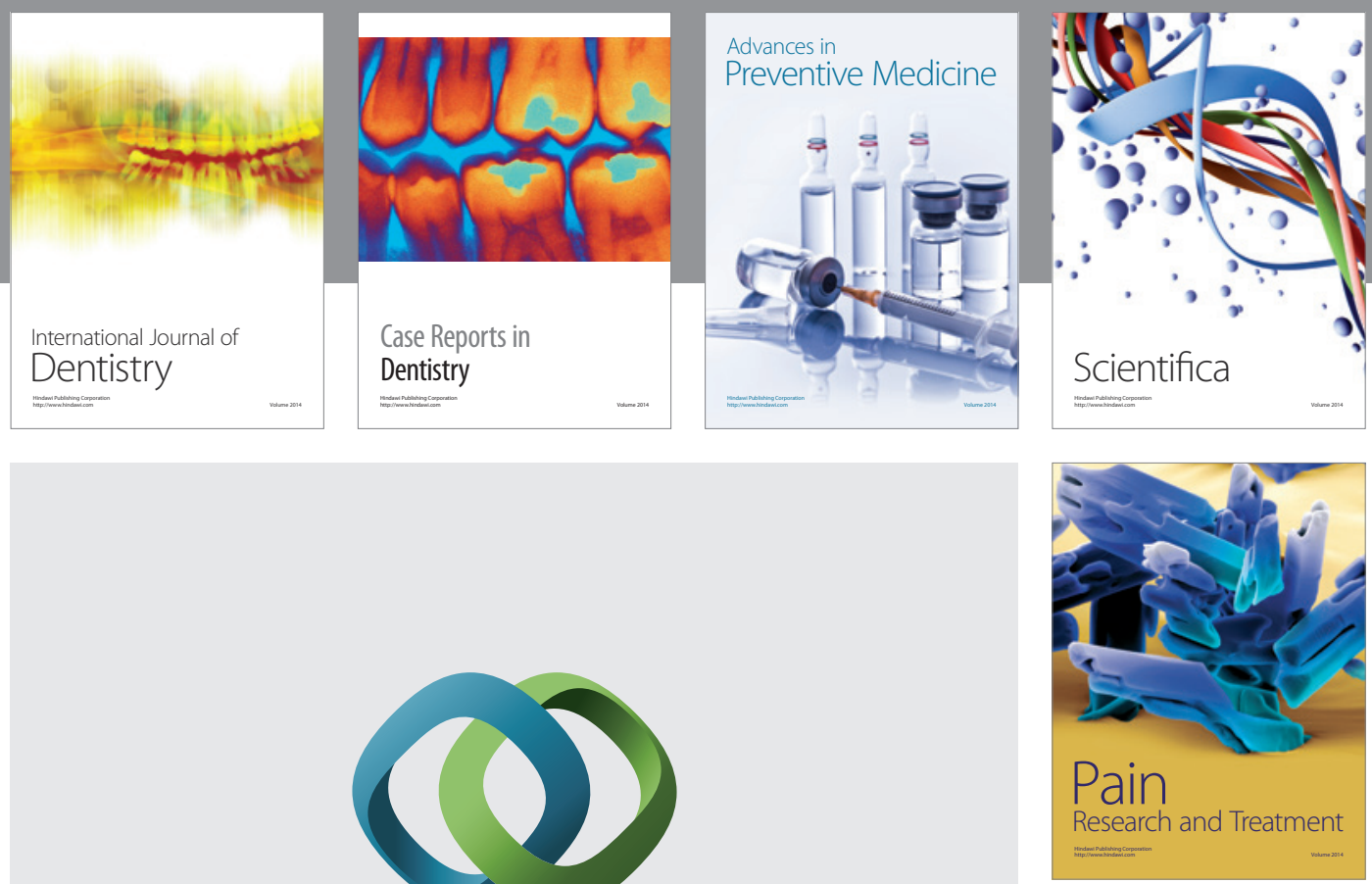

\section{Hindawi}

Submit your manuscripts at

http://www.hindawi.com
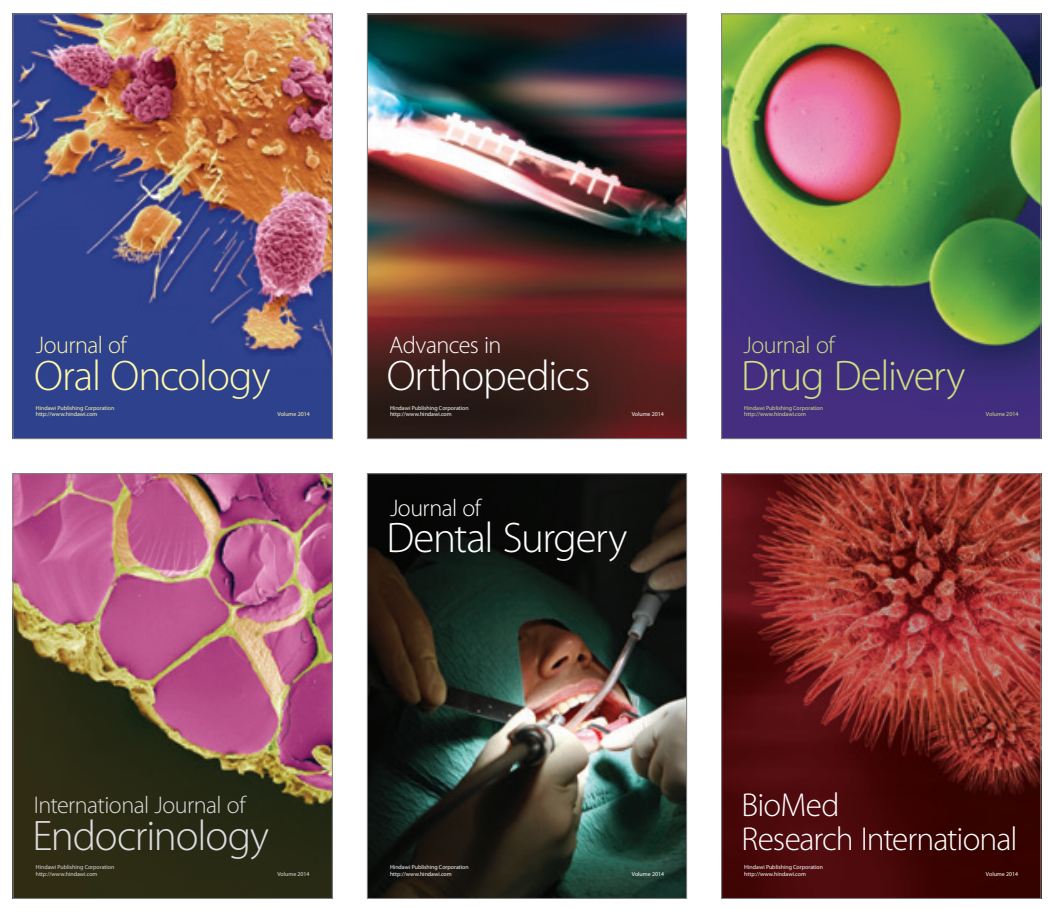

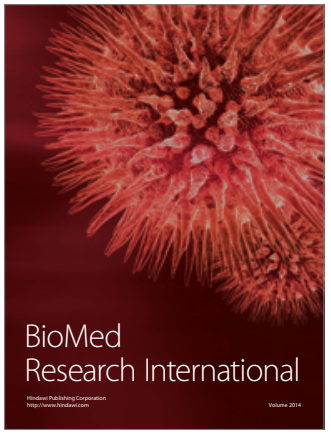

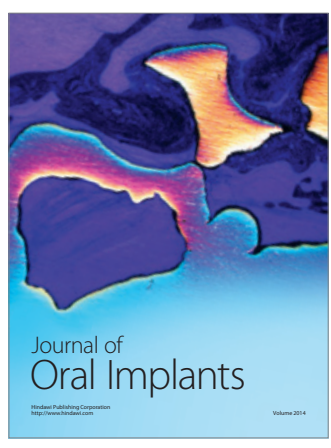
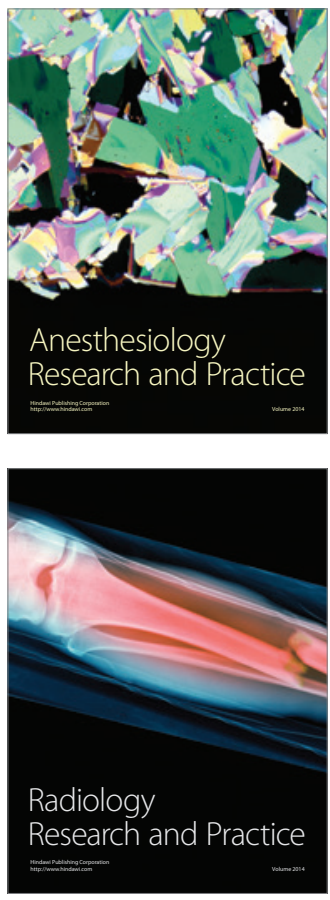